\title{
Review: Coefficients for Stress, Temperature, and Composition Effects in Fluorescence Measurements of Alumina
}

\author{
Robert F. Cook and Chris A. Michaels \\ National Institute of Standards and Technology, \\ Gaithersburg, MD 20899, USA \\ robert.cook@nist.gov \\ chris.michaels@nist.gov
}

\begin{abstract}
The numerical coefficients linearly relating the effects of stress (including pressure), temperature, and composition to shifts in the energies of the Cr-related fluorescence in alumina $\left(\mathrm{Al}_{2} \mathrm{O}_{3}\right)$ are reviewed. The primary focus is the shift of the $\mathrm{R}_{1}$ and $\mathrm{R}_{2}$ "ruby" fluorescence lines under conditions typical for stress determination in polycrystalline $\mathrm{Al}_{2} \mathrm{O}_{3}$. No significant experimental difference in the $R_{1}$ and $R_{2}$ responses is observed for hydrostatic stress (or pressure) conditions (average shift coefficient of about $7.6 \mathrm{~cm}^{-1} / \mathrm{GPa}$ ), changes in temperature (about $0.140 \mathrm{~cm}^{-1} / \mathrm{K}$ ), or variations in composition (about $120 \mathrm{~cm}^{-1} /$ mass fraction of $\mathrm{Cr}$ ). There are significant differences in the $\mathrm{R}_{1}$ and $\mathrm{R}_{2}$ responses for nonhydrostatic stress conditions. In particular, for uniaxial stress along the $a$ and $c$ directions in the $\mathrm{Al}_{2} \mathrm{O}_{3}$ crystal, the $\mathrm{R}_{1}$ piezospectroscopic tensor coefficients (about $3.0 \mathrm{~cm}^{-1} / \mathrm{GPa}$ and $1.6 \mathrm{GPa} \mathrm{cm} / \mathrm{GPa}$, respectively) differ considerably, whereas the $\mathrm{R}_{2}$ coefficients (about $2.6 \mathrm{~cm}^{-1} / \mathrm{GPa}$ and $2.3 \mathrm{GPa} \mathrm{cm}-1 / \mathrm{GPa}$, respectively) do not. Measurements of the piezospectroscopic tensor coefficients are shown to have interlaboratory relative consistency of about $4 \%$ extending over 30 years, and are consistent with the scalar high-pressure measurements. Measurements of the temperature coefficients are shown to have interlaboratory relative consistency less than $1 \%$ extending over 60 years. Fluorescence-based measurements of stress in polycrystalline $\mathrm{Al}_{2} \mathrm{O}_{3}$, although requiring temperature adjustment, are shown to have a relative uncertainty of about $2.5 \%$.
\end{abstract}

Key words: alumina; chromium; crystal; fluorescence; polycrystal; ruby; sapphire; stress; temperature.

Accepted: November 28, 2017

Published: December 13, 2017

https://doi.org/10.6028/jres.122.043

\section{Introduction}

It has long been known that optical states in many compounds arise from the incorporation of "impurities" into the host compound-particularly visible examples are the colors of some oxide minerals [1]. The energies and transition probabilities of the optical states depend on the local atomic environment set by the host surrounding the impurity. In minerals, the states are usually well described by crystal field theory [1], which models the electronic band structure, and hence the optical absorption and emission spectra, of a positively charged impurity ion surrounded by negatively charged host ions arranged in a polygon (e.g., cube, tetrahedron, octahedron) set by the crystal lattice. The host negative ions are usually $\mathrm{O}^{2-}$ ions, and the positive impurity ions are usually first transition series outer electron d-shell ions (e.g., $\mathrm{Fe}^{2+}$ and $\mathrm{Fe}^{3+}$ in garnet and $\mathrm{Cr}^{3+}$ in emerald and ruby). The crystal field refers to the electric field the host ions set up at the impurity ion site, thereby perturbing the electronic structure of the impurity ion. Crystal field effects thus depend sensitively on the size, shape, and symmetry of the negatively charged oxygen ion array surrounding the positively charged impurity ion. Hence, factors that change the size, shape, or symmetry of the negatively charged array, e.g., mechanical stress, will change the crystal field and thus the optical absorption and emission characteristics of a mineral.

In particular, the limited ( $<1 \%$ by mol) substitution of $\mathrm{Cr}^{3+}$ for $\mathrm{Al}^{3+}$ in the $\mathrm{Al}_{2} \mathrm{O}_{3}$ corundum, $\alpha$ alumina, structure leads to the formation of ruby. In its pure form, corundum (often known as "sapphire") 
consists of parallel sheets of triangularly coordinated $\mathrm{O}^{2-}$ ions with $\mathrm{Al}^{3+}$ ions in pairs occupying $2 / 3$ of the octahedral interstices between the sheets [1, 2]. The sheets are perpendicular to the $c$ axis ([0001] direction) of the structure and parallel to three equivalent $a$ axes, $a_{1}, a_{2}, a_{3}(\{2 \overline{1} \overline{1} 0\})$, which are in turn are separated by $120^{\circ}$ and perpendicular to the $c$ axis. The structure is trigonal, but often (well-) approximated as hexagonal. It is convenient to introduce a nonequivalent $m$ axis parallel to the sheets $(\{01 \overline{1} 0\})$ and perpendicular to $a_{1}$, such that $a-m-c$ form a right-handed, perpendicular coordinate system. A schematic diagram is shown in Fig. 1(a). The interstices are trigonally distorted octahedra formed by two triangles of $\mathrm{O}^{2-}$ ions in adjacent sheets; the triangles are rotated by $176^{\circ}$ from each other, reducing the symmetry of the octahedra from $\mathrm{C}_{3 \mathrm{v}}$ to $\mathrm{C}_{3}$ (the symmetry of the lattice is $\mathrm{D}_{3 \mathrm{~d}}$ ). In corundum, the $\mathrm{Al}^{3+}$ ions sit off-center in the octahedra, lying somewhat closer to the "upper," smaller triangle of $\mathrm{O}^{2-}$ ions. Schematic diagrams are shown in Fig. 1(b) and Fig. 1(c). In ruby, $\mathrm{Cr}^{3+}$ ions substitute for some $\mathrm{Al}^{3+}$ ions, occupying similar octahedrally coordinated, off-center lattice positions. The $\mathrm{Cr}^{3+}$ ions are a little bit larger than $\mathrm{Al}^{3+}$ ions, with ionic radii of $64 \mathrm{~nm}$ and $57 \mathrm{~nm}$, respectively, leading to elongation of the substituted octahedron along the $c$ axis [3].
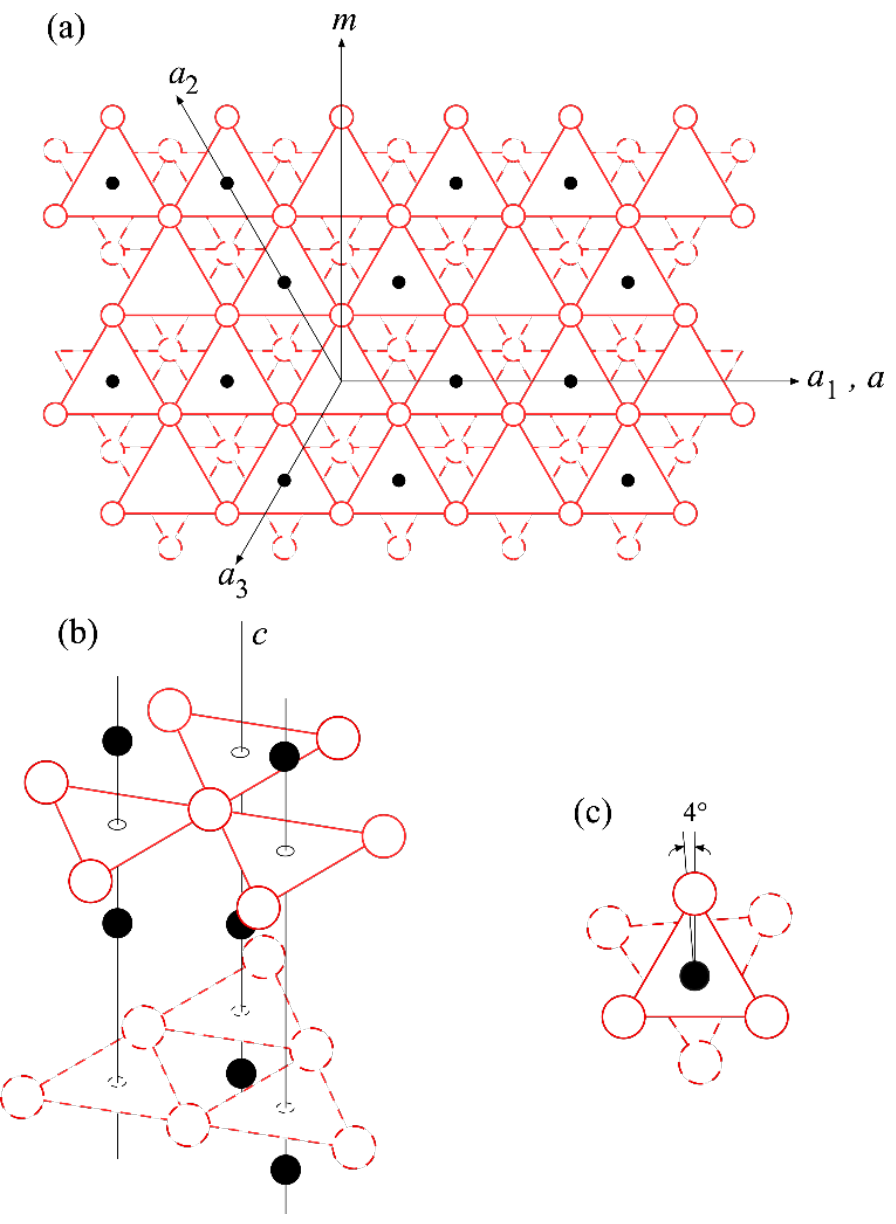

Fig. 1. (a) Schematic plan view of the $\alpha-\mathrm{Al}_{2} \mathrm{O}_{3}$ structure, looking along the $c$ axis and perpendicular to the three equivalent $a_{1}, a_{2}$, and $a_{3}$ axes. The structure consists of triangularly coordinated $\mathrm{O}^{2-}$ ions (large circles) in sheets that alternate in antiparallel orientation along the $c$ axis (the triangular coordination of two adjacent sheets is indicated by the solid and dashed lines). The $\mathrm{Al}^{3+}$ ions (small disks) occupy $2 / 3$ of the interstices between the sheets and are octahedrally coordinated by the $\mathrm{O}^{2-}$ ions. (b) Schematic projection of the $\alpha-\mathrm{Al}_{2} \mathrm{O}_{3}$ structure, looking perpendicular to the $c$ axis. (c) Schematic plan view of the trigonally modified octahedral coordination of $\mathrm{Al}^{3+}$ by $\mathrm{O}^{2-}$ in $\alpha-\mathrm{Al}_{2} \mathrm{O}_{3}$ showing one $\mathrm{O}^{2-}$ triangle (lower, dashed) slightly larger and rotated relative to the other (upper, solid). Figure is after Ref. [1]. The structures in (b) and (c) are idealized as equilateral tringles (see elsewhere for idealized $a$ - and $m$-plane elevations). 
The charged $\mathrm{O}^{2-}$ ions form an electric field, a "crystal field," at the $\mathrm{Cr}^{3+}$ sites, with near-perfect (trigonally modified) octahedral symmetry, removing the degeneracy of the five $d$ orbitals of free-ion $\mathrm{Cr}^{3+}$. An octahedral field leads to a low-energy configuration for $\mathrm{Cr}^{3+}$, consisting of electron occupation of three, low-energy $t_{2 \mathrm{~g}}$ orbitals and two empty, high-energy $e_{\mathrm{g}}$ orbitals. Electron-electron interactions lead to merging of the three $t_{2 \mathrm{~g}}$ orbitals into a singlet ground state labelled (spectroscopically) as ${ }^{4} \mathrm{~A}_{2 \mathrm{~g}}[1]$. Two important excited states for electrons in ruby are the ${ }^{4} \mathrm{~T}_{1 \mathrm{~g}}$ and ${ }^{4} \mathrm{~T}_{2 \mathrm{~g}}$ states, leading to broad optical absorption in the blue (the "Y" band, electron excitation from ${ }^{4} \mathrm{~A}_{2 \mathrm{~g}}$ to ${ }^{4} \mathrm{~T}_{1 \mathrm{~g}}$, about $25000 \mathrm{~cm}^{-1}$ in energy) and in the yellow-green (the " $U$ " band, electron excitation from ${ }^{4} \mathrm{~A}_{2 \mathrm{~g}}$ to ${ }^{4} \mathrm{~T}_{2 \mathrm{~g}}$, about $18000 \mathrm{~cm}^{-1}$ ) regions of the spectrum, but leaving a visible "window" in the red (about $16000 \mathrm{~cm}^{-1}$ and less) region of the spectrum, giving ruby its distinctive red color [2]. The octahedral crystal-field states ${ }^{4} \mathrm{~A}_{2 \mathrm{~g}},{ }^{4} \mathrm{~T}_{1 \mathrm{~g}}$, and ${ }^{4} \mathrm{~T}_{2 \mathrm{~g}}$ are grouptheoretical spin-allowed states deriving from the free-ion ${ }^{4} \mathrm{~F}$ ground state. The state of great importance here is the ${ }^{2} \mathrm{E}$ spin-disallowed doublet state derived from the free-ion ${ }^{2} \mathrm{G}$ excited state. Spin-orbit coupling splits the ${ }^{2} \mathrm{E}$ doublet into two states, leading to two emission lines, $\mathrm{R}_{1}$ and $\mathrm{R}_{2}$, the "ruby" lines, coincidentally red, at energies of approximately $14403 \mathrm{~cm}^{-1}$ and $14443 \mathrm{~cm}^{-1}$ (about $1.79 \mathrm{eV}$, with wavelengths of about $694 \mathrm{~nm}[1,2])$. The process of interest here in ruby is $\mathrm{Y}$ and $\mathrm{U}$ optical absorption of photons, leading to excitation of electrons from the ${ }^{4} \mathrm{~A}_{2 \mathrm{~g}}$ ground state to the ${ }^{4} \mathrm{~T}_{1 \mathrm{~g}}$, and ${ }^{4} \mathrm{~T}_{2 \mathrm{~g}}$ states, followed by internal conversion of the energy of the electrons via the thermal phonon bath to the split ${ }^{2} \mathrm{E}$ states, and, finally, $R_{1}$ and $R_{2}$ radiative fluorescence as the electrons descend from the ${ }^{2} \mathrm{E}$ states back to the ${ }^{4} \mathrm{~A}_{2 \mathrm{~g}}$ ground state (fluorescence lifetime of the ${ }^{2} \mathrm{E}$ states is a few milliseconds [4]). A schematic diagram of the relevant ruby electronic structure is shown in Fig. 2.

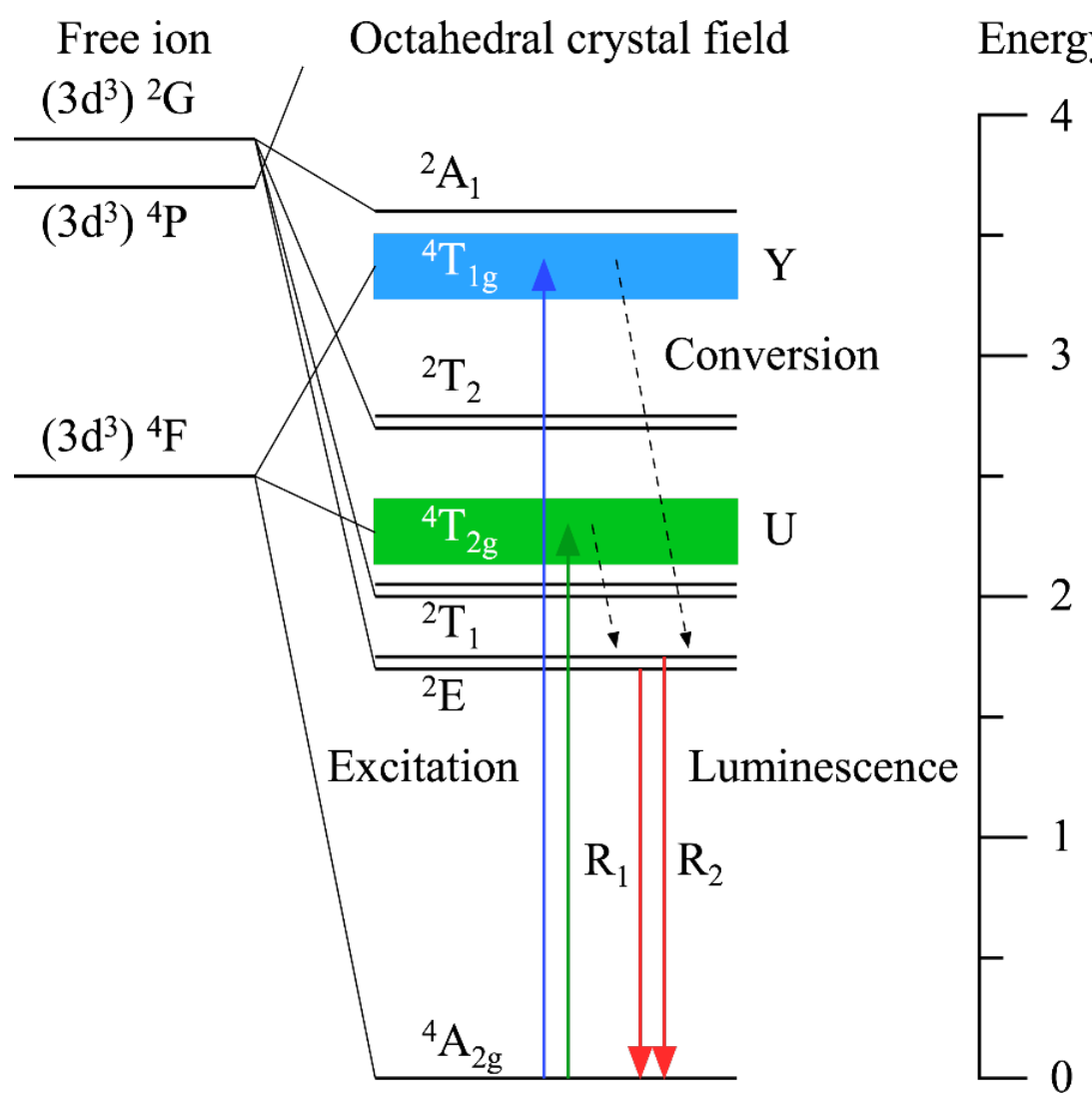

Fig. 2. Schematic diagram of the electronic energy levels of $\mathrm{Cr}^{3+}$ substituting for $\mathrm{Al}^{3+}$ in $\alpha-\mathrm{Al}_{2} \mathrm{O}_{3}$ (ruby). The levels in the trigonally distorted octahedral ruby crystal field are shown in the center; the levels of the excited states of the free $\mathrm{Cr}^{3+}$ ion from which the crystal field levels derive are shown on the left. During ruby fluorescence, electrons are excited from the ${ }^{4} \mathrm{~A}_{2 \mathrm{~g}}$ ground state to two strongly absorbing bands, in the green and blue regions of the spectrum, ${ }^{4} \mathrm{~T}_{2 \mathrm{~g}}$ and ${ }^{4} \mathrm{~T}_{1 \mathrm{~g}}$ (these absorptions are responsible for "ruby red"). The excited electrons interact with phonons in the structure, descending in energy to the split ${ }^{2} \mathrm{E}$ states. The electrons then return to the ground state, emitting $\mathrm{R}_{1}$ and $\mathrm{R}_{2}$ fluorescent photons in the process. Figure is after Ref. [2]. 
Many spectroscopic studies have been performed on ruby and sapphire, investigating the states mentioned above and many others. A strong initial motivation, in the 1950s and 1960s, was testing of the then-nascent crystal field theory using the reasonably well-controlled $\mathrm{Cr}$ in $\mathrm{Al}_{2} \mathrm{O}_{3}$ ruby as the test vehicle [5-13]. An additional practical motivation at that time was detailed knowledge of the electro-optical energies of ruby, so that it could be used as a solid-state maser [14] and laser [15] material. It was clear to the early investigators that any factors straining the $\mathrm{O}^{2-}$ ion arrangement surrounding the $\mathrm{Cr}^{3+}$ ion led to changes in the crystal field and thus changes in the optical absorption and emission. Important factors were externally applied stress mediated by elasticity, temperature via thermal expansion, and composition via ionic radius mismatch. In the early 1970s, the process was turned around somewhat, and the details of crystal field theory were overtaken by empirical advances. In particular, calibrated experimental determination of shifts in the $\mathrm{R}_{1}$ and $\mathrm{R}_{2}$ line energies, $v$, as a function of hydrostatic pressure [16-22] became the standard method for measuring pressure in high-pressure experiments involving the diamond anvil cell (DAC) - a method that continues to this day [23-37], although not without debate regarding calibration coefficients. (Here and throughout, citations within a topic are given in chronological order of publication.) An example of the fluorescence spectra for ruby and sapphire, demonstrating the composition effect, is shown in Fig. 3.

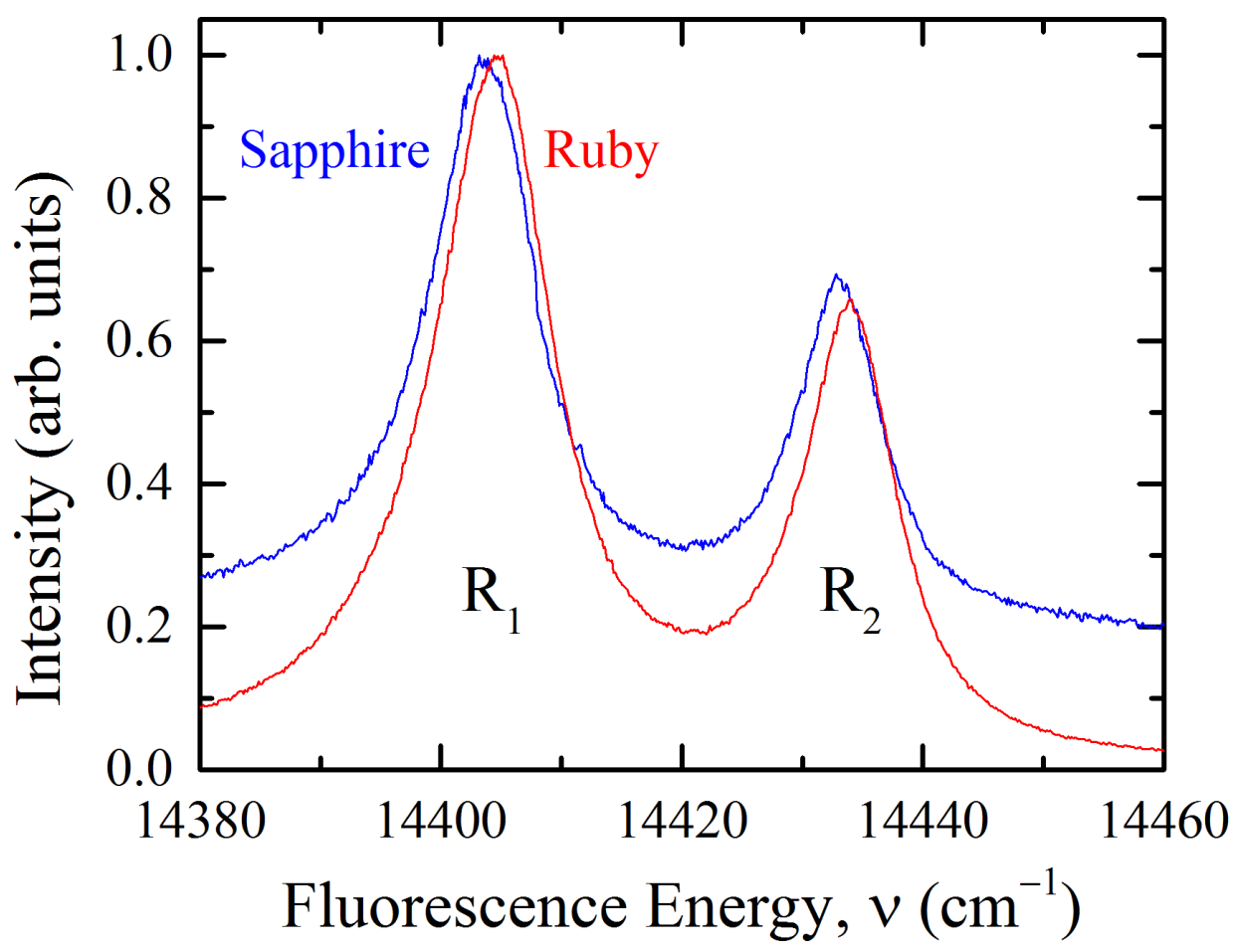

Fig. 3. Fluorescence spectra of single crystal sapphire and ruby, with the $\mathrm{R}_{1}$ and $\mathrm{R}_{2}$ peaks labelled. Sapphire $\left(\alpha-\mathrm{Al}_{2} \mathrm{O}_{3}\right)$ usually contains enough trace $\mathrm{Cr}^{3+}$ to observe the peaks as here. The ruby peaks are shifted relative to the sapphire peaks due to $\mathrm{Cr}^{3+}$ composition effects. The ionic radius of $\mathrm{Cr}^{3+}$ is greater than that of $\mathrm{Al}^{3+}$, such that on substitution of $\mathrm{Cr}^{3+}$ for $\mathrm{Al}^{3+}$, an internal stress field is developed in the crystal, which shifts the fluorescence peaks due to a change in the crystal field. The ruby here contained $0.43 \%$ mass fraction of $\mathrm{Cr}$ in $\mathrm{Al}_{2} \mathrm{O}_{3}$ : $\mathrm{Cr}$. Spectral intensities were adjusted for ease of comparison. 
In the late 1970s, a mechanical model was developed by Grabner for nonhydrostatic loading (i.e., described by a general stress tensor) and applied to polycrystalline alumina [38]. At least part of the motivation for the polycrystalline research was to investigate the stress fields arising in polycrystalline alumina responsible for microcracking - the spontaneous localized cracking that occurs in polycrystalline alumina on cooling as a consequence of the anisotropic structure and thermal expansion of corundum [3941]. From the 1990s onward, although there were many notable fundamental studies of the phenomenon [42-58], the shift in energy of $\mathrm{R}$ lines with stress was largely confined to the applied domain, detailed in numerous works, such as: measurement of stress in bulk $\mathrm{Al}_{2} \mathrm{O}_{3}$ polycrystals [42, 58-67]; in bulk $\mathrm{Al}_{2} \mathrm{O}_{3^{-}}$ $\mathrm{ZrO}_{2}$ composites [68-78]; in sapphire or composite fibers, free or in matrices [79-91]; in single-crystal thin films [92-95]; (particularly) in polycrystalline thick films on thermal barrier coatings [96-119]; and adjacent to introduced indentations, cracks, and scratches in $\mathrm{Al}_{2} \mathrm{O}_{3}$ and its composites [42, 120-134]. The works of Clarke and colleagues are notable for their advances in both the fundamental and applied domains (especially polycrystalline films) and also the works in the applied domain of Young and colleagues (fibers), Pezzotti and colleagues (cracks), and Todd and colleagues (indentations). An example of the shifts in the $R_{1}$ and $R_{2}$ fluorescence peaks arising from stress state changes is shown in Fig. 4.

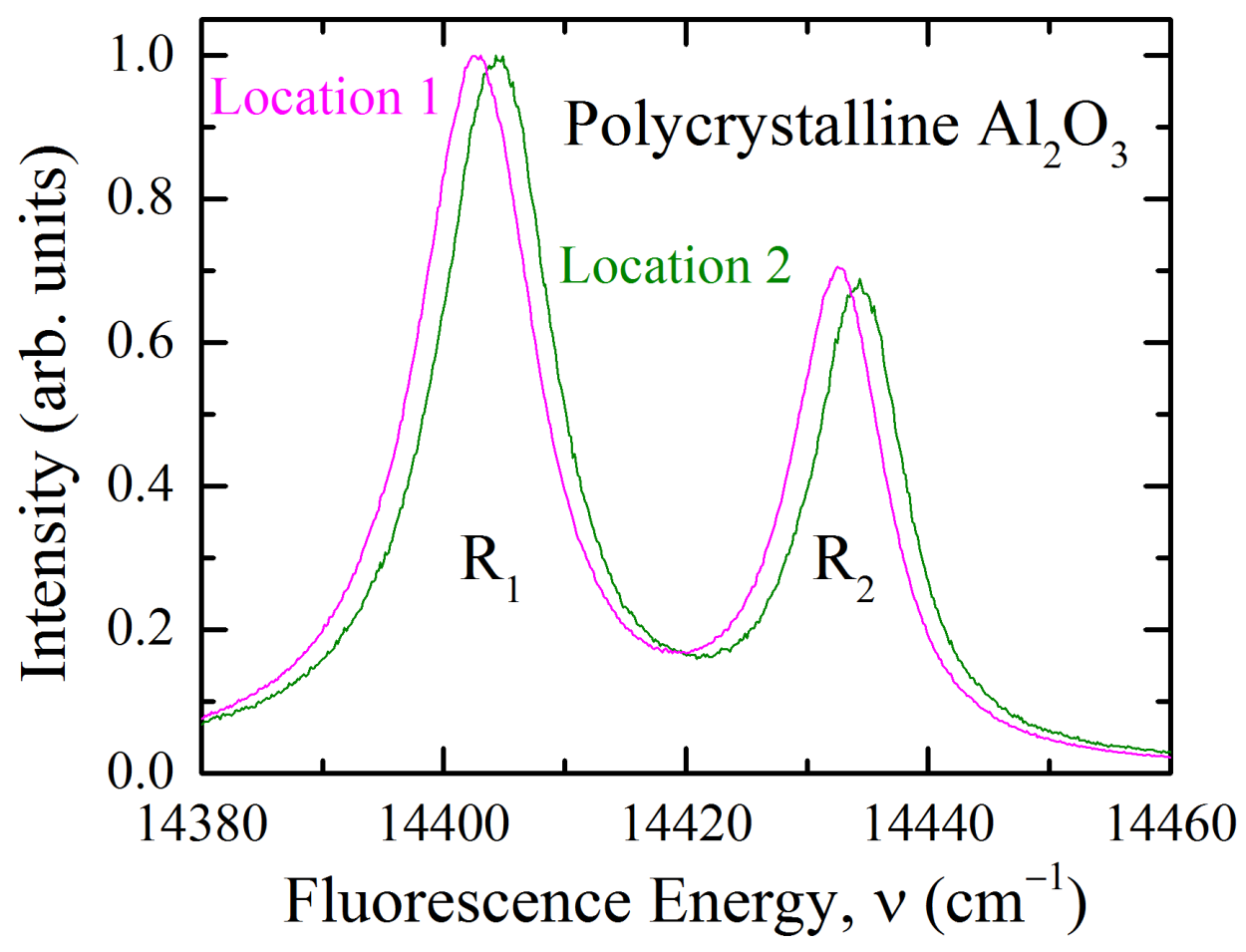

Fig. 4. Fluorescence spectra showing the $\mathrm{R}_{1}$ and $\mathrm{R}_{2}$ peaks obtained from two different locations in a Cr-doped polycrystalline $\mathrm{Al}_{2} \mathrm{O}_{3}$ material. The spectra are shifted relative to one another due to microstructural effects, leading to an internal stress field arising in the polycrystalline material from the thermal expansion anisotropy effects of the constituent $\mathrm{Al}_{2} \mathrm{O}_{3}$ grains. The spectra have been corrected for thermal effects and adjusted in intensity for easy comparison. Figure is after Ref. [67]. 
A feature of all the above work is that the shift in the $\mathrm{R}$ lines with external factors was taken as linear. That is, the shifts in the R-line energies were taken as simply proportional to the stress, temperature, or composition, in the first case as a tensor relation and in the last two as scalar relations. It is true that measured over large pressure or temperature ranges (more than $100 \mathrm{GPa}$ or $100 \mathrm{~K}$, where commonly used units for pressure are $1 \mathrm{Mbar}=100 \mathrm{GPa}, 1 \mathrm{~kg} / \mathrm{cm}^{2}=9.8 \times 10^{4} \mathrm{~Pa}$, and $1 \mathrm{dyn} / \mathrm{cm}^{2}=0.1 \mathrm{~Pa}$ ), the variation of $\mathrm{R}$-line energies is extremely nonlinear (see equations in Ref. [2] used to generate Fig. 5). However, in the range of typical fluorescence measurements on typical polycrystalline alumina structures (variations less than $1 \mathrm{GPa}$, a few Kelvin), the dependence of the energies on stress, temperature, and composition can be taken as linear; see Fig. 5 [135].

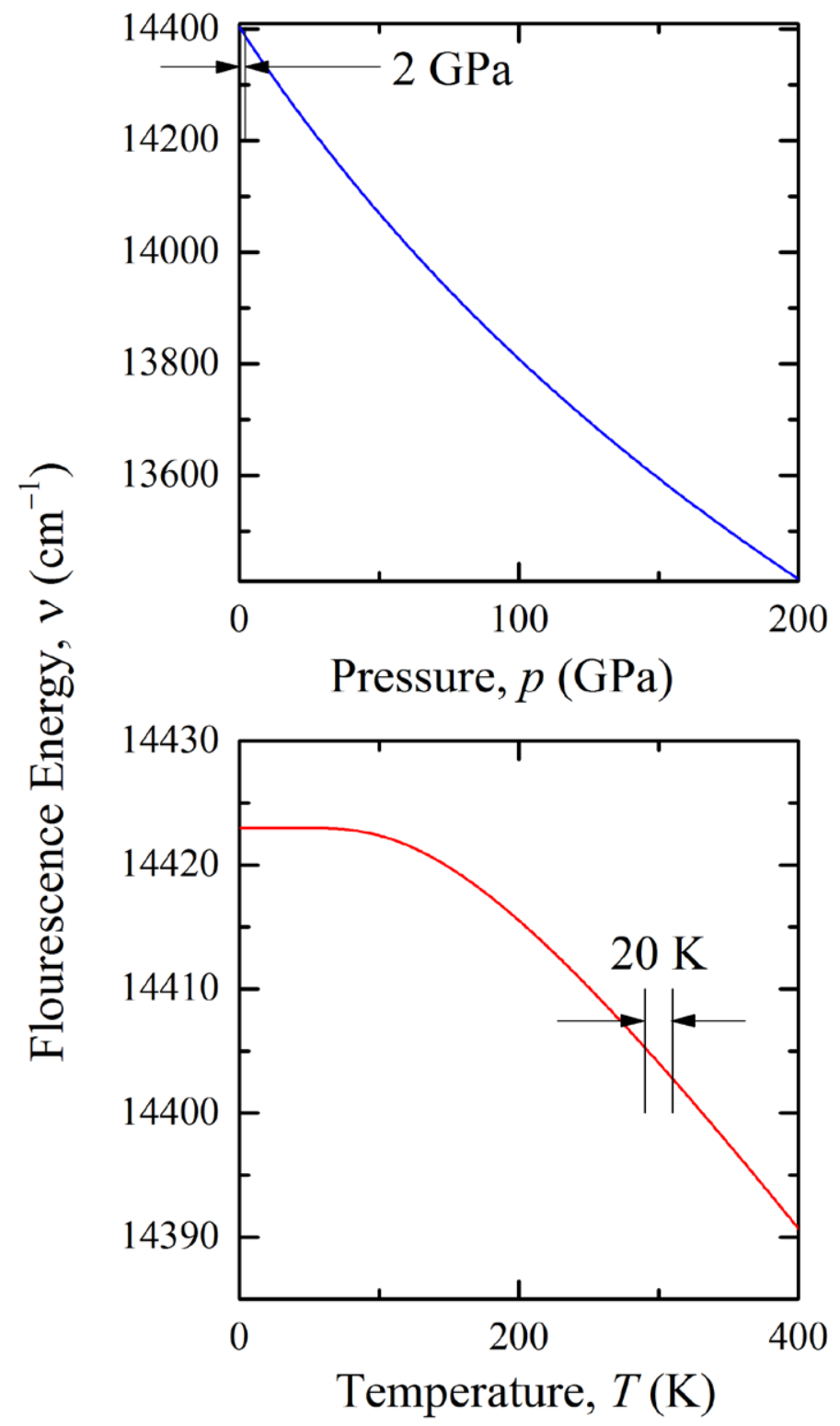

Fig. 5. Variations of $\mathrm{R}_{1}$ fluorescence energy with (a) hydrostatic pressure and (b) temperature. The slight nonlinearity with pressure is only observed in high-pressure apparatus that access extremely high pressures. The small stress range (about 2 GPa) observed in typical $\mathrm{Al}_{2} \mathrm{O}_{3}$ microstructures is indicated and well described by a linear response. The nonlinearity with temperature is only observed in cryogenic apparatus that access extremely low temperatures. The small temperature range (about $20 \mathrm{~K}$ ) occurring in typical measurements of $\mathrm{Al}_{2} \mathrm{O}_{3}$ microstructures is indicated and well described by a linear response. 
Within the small variation approximation, the effects of stress, temperature, and composition are also taken as separable and additive:

$$
\Delta v=\Delta v_{\sigma}+\Delta v_{T}+\Delta v_{C}
$$

where $\Delta v$ is the total shift in the (center) energy of an R-line emission peak, and $\Delta v_{\sigma}, \Delta v_{T}$, and $\Delta v_{C}$ are the individual contributions to the total shift from stress $(\sigma)$, temperature $(T)$, and composition $(C)$ effects, respectively [135]. An example detailing the notation is shown in Fig. 6, where the center frequency in an unaffected system is $v_{0}$ (say, in single-crystal sapphire), such that the total shift is given by $\Delta v=v-v_{0}$ (say, in polycrystalline alumina). Usually, it is stress measurement that is of the most interest, and hence Eq. (1) is often thought of as

$$
\Delta v_{\sigma}=\Delta v-\Delta v_{T}-\Delta v_{C}
$$

where temperature and composition effects "correct" the measured total shift to leave the stress effect. This was the approach taken in two recent papers $[66,67]$ regarding stress measurement in polycrystalline alumina. It was emphasized in those papers and elsewhere that the corrections of Eq. (1a) and the selection of the correct proportionality constants-the coefficients-are critical in accurate and precise stress measurement $[2,136]$. It is the experimental determination of these coefficients that is the subject of this review. The review has several goals: (1) to provide historical context for the coefficients, so that prior work can be judged in terms of new results; (2) to guide selection of the "right" coefficients and, where possible, their accuracy and precision; (3) to guide against wrongly cited or attributed coefficients; (4) to provide (in one place, with common notation) simple relations for common geometries to show how the coefficients are used, including for polycrystals; and (5) to assess the importance of temperature and composition corrections.

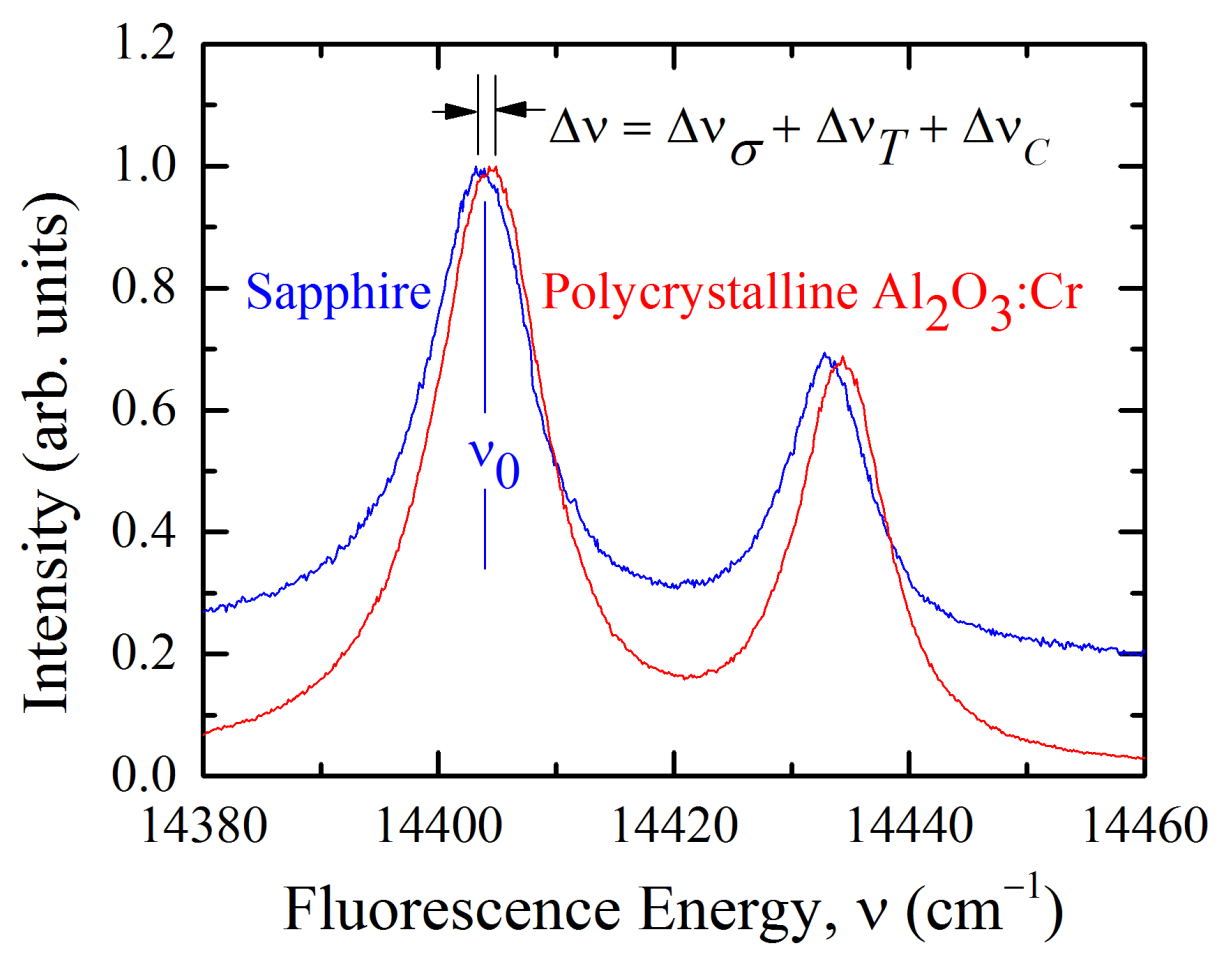

Fig. 6. Fluorescence spectra for sapphire and polycrystalline $\mathrm{Al}_{2} \mathrm{O}_{3}$, showing the $\mathrm{R}_{1}$ and $\mathrm{R}_{2}$ peaks and the notation for peak shift due to stress, temperature, and composition effects. This review emphasizes that the use of the correct coefficients can relate the shifts to stress in the $\mathrm{Al}_{2} \mathrm{O}_{3}$ structure. 


\section{Background Analysis}

This section defines the coefficients that linearly relate the changes in energy of the ruby $\mathrm{R}$ lines to the imposition of stress, changes in temperature, and changes in $(\mathrm{Cr})$ composition of a material. The importance of knowledge of the values of the coefficients (and their uncertainties), which is the focus of the review and the next section, is made clear. The section begins with an analysis of the stress coefficients before moving on to the simpler temperature and composition coefficients.

\subsection{Stress}

The linear analysis relating the scalar shift in energy, $\Delta v_{\sigma}$, due to stress effects alone and the stress tensor acting within a ruby single crystal, $\sigma_{i j}^{*}$, begins with the equation first given by Grabner [38]:

$$
\Delta v_{\sigma}=\Pi_{i j} \sigma_{i j}^{*}
$$

Here, $\sigma_{i j}^{*}$ is defined relative to the crystal coordinate system (denoted by the superscript star, ${ }^{*}$ ), as is the stress-optical or piezospectroscopic tensor $\Pi_{i j}$. The indices $i, j$ each take the values $1,2,3$, corresponding to $a, m, c$ here. The Einstein summation convention is assumed throughout. The piezospectroscopic tensor is assumed to have the same (trigonal) symmetry as the ruby lattice $\left(\mathrm{D}_{3 \mathrm{~d}}\right)$, and consequently the offdiagonal components of the (symmetric, second rank) tensor are zero in the crystal coordinate system. The piezospectroscopic tensor is thus

$$
\Pi_{i j}=\left[\begin{array}{ccc}
\Pi_{11} & 0 & 0 \\
0 & \Pi_{22} & 0 \\
0 & 0 & \Pi_{33}
\end{array}\right]
$$

and Eq. (2) reduces to

$$
\begin{aligned}
\Delta v_{\sigma} & =\Pi_{11} \sigma_{11}^{*}+\Pi_{22} \sigma_{22}^{*}+\Pi_{33} \sigma_{33}^{*} \\
& =\Pi_{\mathrm{a}}\left(\sigma_{11}^{*}+\sigma_{22}^{*}\right)+\Pi_{\mathrm{c}} \sigma_{33}^{*}
\end{aligned}
$$

Two further reductions are possible, one empirical (and very useful) and the other mathematical (and even more useful). The first reduction is that, empirically, $\Pi_{11}=\Pi_{22}$, implying that the piezospectroscopic effect is uniform perpendicular to the crystal axis and takes on the $a$-axis value (similar to elastic and thermal expansion effects). Hence, the notation $\Pi_{11}=\Pi_{22}=\Pi_{a}$ is used; the remaining component is designated $\Pi_{33}=\Pi_{c}$; see the second line of Eq. (4). The second reduction is to note that under hydrostatic compressive loading conditions, the three stress components are equal, $\sigma_{11}^{*}=\sigma_{22}^{*}=\sigma_{33}^{*}=-p$, where $p$ is the pressure. Thus, Eq. (4) becomes the scalar equation

$$
p=-\Delta v_{p} / \Pi_{P}=-\Delta v_{p} /\left(2 \Pi_{a}+\Pi_{c}\right)
$$

which is the basis (when calibrated [16, 20, 21, 25]) for ruby pressure measurement in the DAC and other high-pressure experiments, and which provides insight into the origin of the pressure proportionality constant $\Pi_{p}=\left(2 \Pi_{a}+\Pi_{c}\right)$. Both $\Pi_{a}$ and $\Pi_{c}$ are usually positive and hence pressure decreases the fluorescence energy (or increases the wavelength of the fluorescent light $[16,20]$ ).

Note that a crystal need not be aligned with the $x-y-z$ coordinate system of the sample or laboratory frame (particularly true in polycrystals, but irrelevant in DAC experiments as the pressure field is frame invariant). Note also that the (off-diagonal) shear stresses in the crystal frame are not necessarily zero or assumed to be zero (i.e., that $\sigma_{i j}^{*}=0, i \neq j$ is not necessarily true or assumed), just that the energy shift in Eq. (4) is not sensitive to them. These two concepts can be put together by relating the stress applied in the sample or laboratory (or arbitrary) frame ( $\sigma_{m n}$, no star) to that appearing in the (starred) crystal frame, 


$$
\sigma_{i j}^{*}=a_{i m} a_{j n} \sigma_{m n},
$$

where $a_{i j}$ is the orthogonal transformation matrix relating the two frames [137] (and is frequently the product of three rotation matrices based on Euler angles [43]). Combining Eqs. (2), (3), and (6), the empirical equality $\Pi_{11}=\Pi_{22}$, and the tensor identity $a_{i j} a_{i k}=\delta_{j k}$, where $\delta_{j k}$ is the Krönecker delta, leads to a general expression for the energy shift for a crystal set in a sample or laboratory frame [43],

$$
\begin{aligned}
\Delta v_{\sigma} & =\Pi_{\mathrm{a}}\left(\sigma_{11}+\sigma_{22}+\sigma_{33}\right)+\left(\Pi_{\mathrm{c}}-\Pi_{\mathrm{a}}\right)\left(a_{31}^{2} \sigma_{11}+a_{32}^{2} \sigma_{22}+a_{33}^{2} \sigma_{33}\right) \\
& +2\left(\Pi_{\mathrm{c}}-\Pi_{\mathrm{a}}\right)\left(a_{31} a_{32} \sigma_{12}+a_{32} a_{33} \sigma_{23}+a_{31} a_{33} \sigma_{31}\right) \\
= & \Pi_{\mathrm{a}} \sigma_{i i}+\left(\Pi_{\mathrm{c}}-\Pi_{\mathrm{a}}\right) a_{3 i} a_{3 j} \sigma_{i j} .
\end{aligned}
$$

Equation (7) makes clear the role in the sample or laboratory frame of shear stresses and off-diagonal transformation terms. Equation (7) also makes clear that with the assumption $\Pi_{11}=\Pi_{22}=\Pi_{a}$, Eq. (7) is just a recasting of Eq. (4): There are still only two piezospectroscopic degrees of freedom. In the pressure equation, Eq. (5), which assumes hydrostatic loading, there is only one piezospectroscopic degree of freedom. Equation (7) is also useful because it provides the fluorescence energy shift when the orientation of the crystal is known in the sample or laboratory frame, and hence $a_{i j}$ is known. Such an orientation might be known from X-ray diffraction or electron backscatter diffraction [138] measurements or from prior knowledge of the material, e.g., a polycrystal in which the grain orientations, and hence the $a_{i j}$ values, are distributed randomly [43]. Combining Eq. (7) with the specification of a hydrostatic field, $\sigma_{i j}=$ $-p \delta_{i j}$, and the tensor identity $a_{i j} a_{k j}=\delta_{i k}$ recovers the pressure equation, Eq. (5), showing that the pressure response is indeed frame independent.

Equations (2) and (3) can be combined in a different way, again using the empirical equality $\Pi_{11}=$ $\Pi_{22}$, to give

$$
\begin{aligned}
\Delta v_{\sigma} & =\frac{\left(2 \Pi_{a}+\Pi_{c}\right)\left(\sigma_{11}^{*}+\sigma_{22}^{*}+\sigma_{33}^{*}\right)}{3}+\frac{\left(\Pi_{c}-\Pi_{a}\right)\left(2 \sigma_{33}^{*}-\sigma_{11}^{*}-\sigma_{22}^{*}\right)}{3} \\
& =\left(2 \Pi_{a}+\Pi_{c}\right) \sigma_{\mathrm{M}}+\left(\Pi_{c}-\Pi_{a}\right) \sigma_{\mathrm{S}},
\end{aligned}
$$

where the second line emphasizes that the shift in energy arises from a mean stress contribution $\left(\sigma_{\mathrm{M}}\right)$ plus a shear stress contribution $\left(\sigma_{\mathrm{S}}\right)[67]$ :

$$
\begin{gathered}
\sigma_{\mathrm{M}}=\left(\sigma_{11}^{*}+\sigma_{22}^{*}+\sigma_{33}^{*}\right) / 3, \\
\sigma_{\mathrm{S}}=\left(2 \sigma_{33}^{*}-\sigma_{11}^{*}-\sigma_{22}^{*}\right) / 3 .
\end{gathered}
$$

It should be recognized that the preceding equations, i.e., Eqs. (1-5), (7), and (8), apply to each of the $\mathrm{R}_{1}$ and $\mathrm{R}_{2}$ lines separately. Hence, the coefficients for the stresses in Eq. (8) are strictly defined as

$$
\begin{aligned}
& \Pi_{\mathrm{M}}^{(1)}=\left(2 \Pi_{a}^{(1)}+\Pi_{c}^{(1)}\right), \\
& \Pi_{\mathrm{S}}^{(1)}=\left(\Pi_{c}^{(1)}-\Pi_{a}^{(1)}\right), \\
& \Pi_{\mathrm{M}}^{(2)}=\left(2 \Pi_{a}^{(2)}+\Pi_{c}^{(2)}\right), \\
& \Pi_{\mathrm{S}}^{(2)}=\left(\Pi_{c}^{(2)}-\Pi_{a}^{(2)}\right),
\end{aligned}
$$

where the superscript labels ${ }^{(1)}$ and ${ }^{(2)}$ here and throughout indicate parameters associated with the $\mathrm{R}_{1}$ and $\mathrm{R}_{2}$ lines, respectively. Equation (10) enables Eq. (8) to be written compactly in matrix form for each fluorescent line: 


$$
\left[\begin{array}{l}
\Delta v^{(1)} \\
\Delta v^{(2)}
\end{array}\right]=\left[\begin{array}{cc}
\Pi_{\mathrm{M}}^{(1)} & \Pi_{\mathrm{S}}^{(1)} \\
\Pi_{\mathrm{M}}^{(2)} & \Pi_{\mathrm{S}}^{(2)}
\end{array}\right]\left[\begin{array}{c}
\sigma_{\mathrm{M}} \\
\sigma_{\mathrm{S}}
\end{array}\right]
$$

noting that there are still only two piezospectroscopic degrees of freedom (for each shift). Consequently, two components of the stress field $\left(\sigma_{\mathrm{M}}, \sigma_{\mathrm{S}}\right)$ in the crystallographic frame can be specified through inversion of Eq. (11a) to

$$
\left[\begin{array}{c}
\sigma_{\mathrm{M}} \\
\sigma_{\mathrm{S}}
\end{array}\right]=\left(\Pi_{\mathrm{M}}^{(1)} \Pi_{\mathrm{S}}^{(2)}-\Pi_{\mathrm{S}}^{(1)} \Pi_{\mathrm{M}}^{(2)}\right)^{-1}\left[\begin{array}{cc}
\Pi_{\mathrm{S}}^{(2)} & -\Pi_{\mathrm{S}}^{(1)} \\
-\Pi_{\mathrm{M}}^{(2)} & \Pi_{\mathrm{M}}^{(1)}
\end{array}\right]\left[\begin{array}{l}
\Delta v^{(1)} \\
\Delta v^{(2)}
\end{array}\right],
$$

using the two energy shift measurements $\left(\Delta v^{(1)}, \Delta v^{(2)}\right)$. A similar analysis can be applied if the stress field in the crystallographic coordinates is assumed to be rotationally invariant perpendicular to the $c$ axis, such that only two stress components in the crystallographic frame need be specified, $\sigma_{11}^{*}=\sigma_{22}^{*}=\sigma_{\mathrm{a}}$ and $\sigma_{33}^{*}=$ $\sigma_{\mathrm{c}}$. Equation (4) can then be written and inverted as Eq. (11).

Finally, Eqs. (4) and (6) can be combined to give the shift in the sample or laboratory frame, averaged over a large number of randomly oriented grains:

$$
\overline{\Delta v_{\sigma}}=\left(\frac{1}{3}\right) \Pi_{i i} \overline{\sigma_{j j}}=\left(\frac{1}{3}\right)\left(\Pi_{11}+\Pi_{22}+\Pi_{33}\right)\left(\overline{\sigma_{11}+\sigma_{22}+\sigma_{33}}\right),
$$

where the overbar indicates an ensemble average, and the averages $\overline{a_{i j}^{2}}=1 / 3$ and $\overline{a_{i j} a_{i k}}=0$, where $j \neq k$ [43], have been used. There is only one piezospectroscopic degree of freedom as the assumption of a random collection of grains has been made in deriving Eq. (12). One of the simplest examples is the simple bending of a polycrystalline beam, in which the fluorescent measurement encompasses many grains [42]. In this case, $\sigma_{11}=\sigma_{\mathrm{u}}=M z / I$, and $\sigma_{22}=\sigma_{33}=0$, where $M$ here is the bending moment applied to the beam, $I$ is the beam moment of inertia, $z$ is the distance from the neutral axis, and $\sigma_{\mathrm{u}}$ is the resulting uniaxial stress at $z$. Another simple example is the biaxial stressing of a polycrystalline film on a thermal expansion mismatched substrate, in which again the fluorescence measurements encompass many grains [96]. Here, $\sigma_{11}=\sigma_{22}=\sigma_{\mathrm{b}}$, and $\sigma_{33}=0$, where $\sigma_{\mathrm{b}}$ is the film-substrate mismatch imposed biaxial stress. In the first case,

$$
\overline{\Delta v_{\sigma}}=\left(\frac{1}{3}\right)\left(2 \Pi_{\mathrm{a}}+\Pi_{\mathrm{c}}\right) \sigma_{\mathrm{u}}
$$

and in the second,

$$
\overline{\Delta v_{\sigma}}=\left(\frac{2}{3}\right)\left(2 \Pi_{\mathrm{a}}+\Pi_{\mathrm{c}}\right) \sigma_{\mathrm{b}} .
$$

Both equations apply separately to the $\mathrm{R}_{1}$ and $\mathrm{R}_{2}$ lines, although, as will be seen, experimentally the distinction between the lines is not meaningful. The similarity of these equations to the pressure relation, Eq. (5), is clear.

\subsection{Temperature and Composition}

The shifts in the R-line fluorescence energy with temperature and composition in typical measurements on alumina are simple proportionalities. The shift with temperature, $T(\mathrm{~K})$, is given by

$$
\Delta v_{T}=\beta_{T}\left(T-T_{\mathrm{ref}}\right)
$$

where $T_{\text {ref }}$ is a reference temperature (taken as $298.8 \mathrm{~K}$, following Munro [135]), and $\beta_{T}$ is the proportionality coefficient. Under normal circumstances, $\beta_{T}$ is negative, such that the fluorescence energy decreases with increasing temperature (see Fig. 5). 
The shift with composition, $C$, is given by a relation similar to Eq. (13) but with no reference point:

$$
\Delta v_{C}=\beta_{C} C
$$

where $C$ is the $\mathrm{Cr}$ composition given by the mass fraction (not percentage [139]) of $\mathrm{Cr}$ in the $\mathrm{Al}_{2} \mathrm{O}_{3}: \mathrm{Cr}$ structure [66]. $\beta_{C}$ is positive, such that fluorescence energy increases with $\mathrm{Cr}$ content. Both $\beta_{T}$ and $\beta_{C}$ are different for the $\mathrm{R}_{1}$ and $\mathrm{R}_{2}$ lines.

Although not exhaustive, the applications mentioned in the Introduction and the formulae presented in this analysis section should make clear that measurement of the energies of the $R_{1}$ and $R_{2}$ fluorescent lines in alumina provides a powerful method for noncontact local measurement of stress. It should be equally clear that the accuracy and precision of such measurements depend on knowledge of the coefficients $\Pi_{\mathrm{a}}, \Pi_{\mathrm{c}}, \beta_{T}$, and $\beta_{C}$ for each line. The following section, which is the focus of the review, examines the experimental development of the numerical values of these coefficients.

\section{Coefficient Measurements}

Despite the 65 year period spanned by the papers covered in this review, the many instruments used to measure the coefficients reviewed here were broadly similar in basic functionality. Each instrument utilized a visible light source for excitation of the $\mathrm{Cr}^{3+}$ fluorescence and high-resolution dispersive detection for measuring the precise energy of the $\mathrm{R}_{1}$ and $\mathrm{R}_{2}$ fluorescence transitions. Early measurements utilized lamp and filter combinations for excitation (e.g., Ref. [140]); by the early 1980s, visible lasers had replaced the lamp sources [23]. Spectral measurements were typically made with a scanning grating monochromator with a single element detector, until parallel spectral detection schemes with diode arrays or charged coupled devices became common in the late 1990s [141]. Each instrument also employed a cell for mounting the alumina specimen in a specific geometry with a means for controlling the external applied stress and the temperature. The majority of instruments used microscope objective lenses of modest magnification (e.g., 10×) for both the excitation and detection of fluorescence in both transmitted light and reflection (as in Figs. 3, 4, 6) geometries, yielding spot sizes in the tens of micrometers. A typical implementation of these instrumental features consisted of a DAC mounted in an upright optical microscope coupled to a grating monochromator. Barnett and coworkers presented a detailed description of this type of system [17].

\subsection{Hydrostatic Pressure Loading}

The measurements of the energy changes of the ruby R-lines with hydrostatic pressure provide not only useful qualitative background for uniaxial stress measurements (next section), but quantitative constraints that the uniaxial measurements must meet. Qualitatively, hydrostatic measurements are simple to understand and compare, Eq. (5) is scalar, and provide a measure of the effect. Quantitatively, hydrostatic measurements provide a pressure coefficient that constrains the sum of the uniaxial coefficients, via Eq. (5).

Table 1 gives the first author, year published, citation, $\mathrm{R}$-line coefficients $\left(\mathrm{R}_{1}\right.$ or $\left.\mathrm{R}_{2}\right)$, and notes for original works that (experimentally) determined the pressure coefficients in Eq. (5), $\Pi_{p}^{(1)}$ and $\Pi_{p}^{(2)}$, directly. Where necessary, the coefficients have been converted to a common set of units ( $\left.\mathrm{cm}^{-1} / \mathrm{GPa}\right)$. In the linear, low-pressure range, the coefficient was often given as

$$
\Delta \lambda / \Delta p
$$

where $\lambda$ is the wavelength of the fluorescence. It is easy to show (using $\lambda \sim 1 / v$ ) that

$$
\frac{\Delta v}{\Delta p}=\Pi_{p}=-\frac{1}{\lambda^{2}} \frac{\Delta \lambda}{\Delta p}
$$


and calculate the coefficient using $\lambda=\lambda_{0}$, where $\lambda_{0}$ is the wavelength of an unaffected system (here 694.24 $\mathrm{nm})$. In the full, nonlinear range, including high pressure, the variation is often given in the form proposed by Mao et al. [25],

$$
p=\left(\frac{A}{B}\right)\left[\left(\frac{\Delta \lambda}{\lambda_{0}}\right)^{B}-1\right],
$$

where $A$ and $B$ are empirical fitting parameters. This equation can be inverted to give (as used in Fig. 5)

$$
\frac{\Delta v}{v_{0}}=\left[p\left(\frac{B}{A}\right)+1\right]^{\left(-\frac{1}{B}\right)}-1
$$

which, in the low-pressure limit, reverts to

$$
\frac{\Delta v}{\Delta p}=\Pi_{p}=\frac{v_{0}}{A}
$$

to calculate the coefficient. A dash in Table 1 indicates a coefficient was not specified. Where not given, uncertainties were not specified. Uncertainties in parentheses $( \pm x)$ represent an estimate based on information given in the publication. Otherwise, unless noted, uncertainties are those specified in the publication and represent standard deviations of the means of experimental measurements. Most determinations used DAC measurements. The pressures given are those up to which the authors observed a linear variation of fluorescence shift with pressure and reported a coefficient, although, in some cases, linear behavior to greater pressures (a few tens of gigapascals) [16, 17, 20] was observed. The term “extrapolated" implies that observations were made over the full pressure range, including high pressure, and extrapolated into the low-pressure range to obtain a coefficient. As noted by Chijioke [34], this linear,

\begin{tabular}{|c|c|c|c|}
\hline Author & $\begin{array}{c}\text { Coefficient, } \\
\Pi_{P}^{(1)}\left(\mathrm{cm}^{-1} / \mathrm{GPa}\right) \\
\end{array}$ & $\begin{array}{c}\text { Coefficient, } \\
\Pi_{P}^{(2)}\left(\mathrm{cm}^{-1} / \mathrm{GPa}\right)\end{array}$ & Notes \\
\hline $\begin{array}{l}\text { Paetzold, } 1951 \text { [142] } \\
\text { pressure up to } 0.1 \mathrm{GPa}\end{array}$ & 9.4 & 8.3 & $290 \mathrm{~K}$ \\
\hline $\begin{array}{l}\text { Langer, } 1967 \text { [143] } \\
\text { pressure up to } 1 \mathrm{GPa}\end{array}$ & $9.0 \pm 0.5$ & $9.0 \pm 0.5$ & \\
\hline $\begin{array}{c}\text { Forman, } 1972[16] \\
\text { pressure up to } 2.2 \mathrm{GPa}\end{array}$ & $7.7 \pm 0.3$ & $8.4 \pm 0.3$ & \\
\hline $\begin{array}{c}\text { Barnett, } 1973[17] \\
\text { pressure up to } 10 \mathrm{GPa}\end{array}$ & $7.5( \pm 0.4)$ & $7.5( \pm 0.4)$ & “accurate to approximately $10 \%$ " \\
\hline $\begin{array}{c}\text { Piermarini, } 1975 \text { [20] } \\
\text { pressure up to } 19.5 \mathrm{GPa}\end{array}$ & $7.572 \pm 0.044$ & - & “95 \% confidence interval” \\
\hline $\begin{array}{c}\text { Adams, } 1976[21] \\
\text { pressure up to } 5 \mathrm{GPa}\end{array}$ & $7.3 \pm 0.2$ & $7.3 \pm 0.2$ & $166.8 \mathrm{~K}$ \\
\hline Mao, 1978 [22] & $7.57( \pm 0.45)$ & - & $\begin{array}{l}\text { extrapolated from fit function } \\
\text { "total random error } \ldots \pm 6 \% \text { " }\end{array}$ \\
\hline $\begin{array}{c}\text { Munro, } 1985 \text { [135] } \\
\text { pressure up to 14.5 GPa }\end{array}$ & $7.59 \pm 0.04$ & $7.615 \pm 0.004$ & “99 \% confidence level” \\
\hline Мao, 1986 [25] & 7.56 & - & extrapolated from fit function \\
\hline Eggert, 1989 [26] & 7.6 & 7.6 & extrapolated from graph \\
\hline $\begin{array}{c}\text { Ragan, } 1996 \text { [144] } \\
\text { pressure up to 15 GPa }\end{array}$ & 7.6 & - & \\
\hline $\begin{array}{c}\text { He, } 1999[88] \\
\text { pressure up to } 5 \mathrm{GPa}\end{array}$ & 7.65 & 7.56 & polycrystal \\
\hline $\begin{array}{l}\text { Grasset, } 2001 \text { [136] } \\
\text { pressure up to } 1 \mathrm{GPa}\end{array}$ & $7.68( \pm 0.15)$ & $7.79( \pm 0.15)$ & $95 \%$ confidence interval \\
\hline Chijioke, 2005, Silvera 2007 [34, 35] & $7.678 \pm 0.027$ & $7.678 \pm 0.027$ & extrapolated from fit function \\
\hline
\end{tabular}
low-pressure range extends experimentally up to many tens of gigapascals.

Table 1. Pressure coefficients for R-line shifts in alumina. 
Table 1 shows that the initial measurements of $\Pi_{p}$ were probably overestimates, that the accepted value, about $7.6 \mathrm{~cm}^{-1} / \mathrm{GPa}$, was established in the 1970s, and that the effect of hydrostatic pressure was the same for both $\mathrm{R}_{1}$ and $\mathrm{R}_{2}$ (i.e., $\Pi_{p}^{(1)}=\Pi_{p}^{(2)}$ ). In fact, this last observation is now taken as an indication of pure hydrostatic (i.e., zero shear) loading in high-pressure DAC experiments that make use of Eq. (5) in determining pressure [34]. The overall (between-laboratory) uncertainty in $\Pi_{p}$ can be estimated from Table 1 as about $0.07 \mathrm{~cm}^{-1} / \mathrm{GPa}$, and this is consistent with the total variation (about $0.14 \mathrm{~cm}^{-1} / \mathrm{GPa}$ ) of mean " $A$ " values in two compilations [2,145] of high-pressure measurements. (The values quoted here are representative of the historical variability and are not the result of statistical calculation.) On a practical note, the information in Table 1 states that the numerical proportionality relationships for energy shift in a random polycrystal under uniaxial stress, equibiaxial stress, and equitriaxial stress (negative pressure) (in the ratios 1/3:2/3:1, see above) are $\sigma_{\mathrm{u}}=\Delta v_{\sigma} / 2.5, \sigma_{\mathrm{b}}=\Delta v_{\sigma} / 5.1$, and $p=-\Delta v_{\sigma} / 7.6$.

\subsection{Uniaxial Stress Loading}

\subsubsection{Quasi-Static Tests}

Table 2. Stress coefficients ${ }^{\mathrm{a}}$ for R-line shifts in alumina.

\begin{tabular}{|c|c|c|c|c|c|c|c|c|}
\hline Author & $\Pi_{a}^{(1)}$ & $\Pi_{m}^{(1)}$ & $\Pi_{c}^{(1)}$ & $\begin{array}{c}\text { Inferred } \\
\text { Pressure } \\
\text { Coefficient, } \\
\Pi_{p}^{(1)}\end{array}$ & $\Pi_{a}^{(2)}$ & $\Pi_{m}^{(2)}$ & $\Pi_{c}^{(2)}$ & $\begin{array}{c}\text { Inferred } \\
\text { Pressure } \\
\text { Coefficient, } \\
\Pi_{p}^{(2)}\end{array}$ \\
\hline $\begin{array}{c}\text { Schawlow, } 1961 \\
{[140]} \\
\text { stress to }-0.1 \mathrm{GPa}\end{array}$ & $\begin{array}{c}3.07 \pm \\
0.07\end{array}$ & - & $\begin{array}{c}1.83 \pm \\
0.01\end{array}$ & $7.97 \pm 0.14$ & $\begin{array}{c}2.75 \pm \\
0.04\end{array}$ & - & $\begin{array}{c}2.35 \pm \\
0.03\end{array}$ & $7.85 \pm 0.09$ \\
\hline $\begin{array}{c}\text { Kaplyanskii, } 1962 \\
{[146]} \\
\text { stress unknown }\end{array}$ & 3.1 & & 1.4 & 7.6 & 2.7 & & 1.9 & 7.3 \\
\hline $\begin{array}{c}\text { Sturge, } 1965 \\
{[147]} \\
\text { stress unknown }\end{array}$ & & & & & & & $\begin{array}{c}\Pi_{\mathrm{c}}^{(1)}+ \\
\mathbf{0 . 5 7 \pm} \pm \\
\mathbf{0 . 0 4}\end{array}$ & \\
\hline $\begin{array}{c}\text { Feher, 1968 } \\
{[148]} \\
\text { stress to }-0.9 \mathrm{GPa}\end{array}$ & $\begin{array}{c}\mathbf{2 . 8} \pm \mathbf{0 . 1} \\
2.70 \pm \\
0.04\end{array}$ & $2.6 \pm 0.2$ & $\begin{array}{c}2.15 \pm \mathbf{0 . 1} \\
1.83 \pm \\
0.03\end{array}$ & $7.23 \pm 0.09$ & $\begin{array}{c}\mathbf{2 . 8} \pm \mathbf{0 . 1} \\
2.28 \pm \\
0.02\end{array}$ & $2.6 \pm 0.2$ & $\begin{array}{c}2.15 \pm \mathbf{0 . 1} \\
2.38 \pm \\
0.03\end{array}$ & $6.94 \pm 0.05$ \\
\hline $\begin{array}{c}\text { Fujishiro, } 1988 \\
{[149]} \\
\text { stress to }-1.2 \mathrm{GPa}\end{array}$ & $\begin{array}{c}2.939 \pm \\
0.041\end{array}$ & & $\begin{array}{c}1.616 \pm \\
0.066\end{array}$ & $7.49 \pm 0.09$ & $\begin{array}{c}2.062 \pm \\
0.102\end{array}$ & & $\begin{array}{c}2.112 \pm \\
0.094\end{array}$ & $6.24 \pm 0.17$ \\
\hline $\begin{array}{c}\mathrm{He}, 1995 \\
{[45]} \\
\text { stress to }-0.9 \mathrm{GPa}\end{array}$ & $\begin{array}{c}\mathbf{2 . 5 6} \\
3.12 \pm \\
0.04\end{array}$ & $\begin{array}{c}3.5 \\
3.40 \pm \\
0.01\end{array}$ & $\begin{array}{c}\mathbf{1 . 5 3} \\
1.55 \pm \\
0.02\end{array}$ & $\begin{array}{c}7.59 \\
8.07 \pm 0.05\end{array}$ & $\begin{array}{c}\mathbf{2 . 6 5} \\
2.66 \pm \\
0.02\end{array}$ & $\begin{array}{c}\mathbf{2 . 8 0} \\
2.81 \pm \\
0.02\end{array}$ & $\begin{array}{c}\mathbf{2 . 1 6} \\
2.22 \pm \\
0.02\end{array}$ & $\begin{array}{c}\mathbf{7 . 6 1} \\
7.69 \pm 0.03\end{array}$ \\
\hline Mean & $\begin{array}{c}2.87 \pm \\
0.06\end{array}$ & $\begin{array}{c}2.95 \pm \\
0.55\end{array}$ & $\begin{array}{c}1.65 \pm \\
0.04\end{array}$ & $7.67 \pm 0.11$ & $\begin{array}{c}2.49 \pm \\
0.07\end{array}$ & $\begin{array}{c}2.70 \pm \\
0.10\end{array}$ & $\begin{array}{c}2.19 \pm \\
0.07\end{array}$ & $7.20 \pm 0.12$ \\
\hline $\begin{array}{c}\text { Constrained } \\
\text { Values }\end{array}$ & 2.98 & - & 1.64 & 7.60 & 2.64 & - & 2.32 & 7.60 \\
\hline
\end{tabular}

${ }^{\mathrm{a}}$ All coefficients are given in $\left(\mathrm{cm}^{-1} / \mathrm{GPa}\right)$.

Table 2 gives the first author, year published, citation, and R-line coefficients $\left(\mathrm{R}_{1}\right.$ or $\left.\mathrm{R}_{2}\right)$ for original works that (experimentally) determined the stress coefficients for different crystal orientations, $\Pi_{a}^{(1)}, \Pi_{m}^{(1)}$, and $\Pi_{c}^{(1)}$ and $\Pi_{a}^{(2)}, \Pi_{m}^{(2)}$, and $\Pi_{c}^{(2)}$, directly; see Eq. (4). Allowance is made for the possibility $\Pi_{m}^{(x)} \neq \Pi_{a}^{(x)}$ where such measurements were made. Values in bold font indicate specification in the original publication. The compressive stresses given are those to which the authors observed a linear variation of fluorescence shift with stress and reported a coefficient. A dash indicates a coefficient was not specified. Where not given, uncertainties were not specified. Where necessary, the coefficients have been converted to a common set of units ( $\left.\mathrm{cm}^{-1} / \mathrm{GPa}\right)$. Values in regular font indicate coefficients and their uncertainties (standard deviations of fitting parameters) determined from digitizing and linear best-fitting data provided in graphical form in original publications. The inferred pressure coefficients were determined from $\Pi_{p}^{(x)}=$ $\Pi_{a}^{(x)}+\Pi_{m}^{(x)}+\Pi_{c}^{(x)}$ or $\Pi_{p}^{(x)}=2 \Pi_{a}^{(x)}+\Pi_{c}^{(x)}$, Eqs. (4) and (5); uncertainties (standard deviations) for the 
$\Pi_{p}^{(x)}$ values were determined by summing uncertainties from the individual coefficients in quadrature. That is, the uncertainty in $\Pi_{p}, u(p)=\left[u^{2}\left(\Pi_{a}\right)+u^{2}\left(\Pi_{m}\right)+u^{2}\left(\Pi_{c}\right)\right]^{1 / 2}$, and so forth, where $u\left(\Pi_{i}\right)$ is the uncertainty in a single coefficient. Mean values were determined by averaging the observed coefficients in each column. Uncertainties (standard deviations) for the mean values were determined by summing uncertainties from the column coefficients in quadrature (as stated). The mean values and uncertainties reflect the broad observations and are for ease of comparison only, and no distinction was made between column parameters. The constrained values reflect the two-parameter constraint sum of Eq. (5) and the experimental observations of Table 1 ; the observed mean $\Pi_{c}^{(x)}$ values were multiplied by the ratio of the observed mean inferred $\Pi_{p}^{(x)}$ values/7.60, and the $\Pi_{a}^{(x)}$ values were adjusted accordingly to meet the constraint of Eq. (5).

The stress coefficients of Table 2 display a much weaker historical variation (larger to smaller values) than the pressure coefficients of Table 1 , reflecting more modern measurements. The calculated mean values thus provide the following broad trends: The pressure coefficients inferred from the uniaxial stress measurements are very close to those observed in hydrostatic tests (about $7.6 \mathrm{~cm}^{-1} / \mathrm{GPa}$ ); the $\Pi_{a}^{(x)}$ values are greater than the $\Pi_{c}^{(x)}$ values, though more so for the $\mathrm{R}_{1}$ peaks (nearly a factor of two) than the $\mathrm{R}_{2}$ peaks (nearly equal); where measured, the $\Pi_{m}^{(x)}$ values are greater than the $\Pi_{a}^{(x)}$ values, although this observation is barely significant; and, based on the first and last observations, the constrained values of the $\Pi_{\mathrm{a}}^{(x)}$ and $\Pi_{\mathrm{c}}^{(x)}$ coefficients are a faithful representation of all the observations. Within experimental uncertainty, the off-diagonal terms $\Pi_{12}=\Pi_{23}=\Pi_{31}=0$ [45], consistent with Eq. (3). (The discrepancies between some published and digitized values in Table 2, e.g., $\Pi_{a}^{(1)}$ from Ref. [45], probably arise from fitting the data to a quadratic equation of the form $\Delta v=c_{1} \sigma+c_{2} \sigma^{2}$ and publishing $c_{1}$ as $\Pi$. This is incorrect within the spirit of the analysis and inconsistent with measurements over a broad pressure range in which nonlinearity only appears at very high pressures, e.g., Fig. 5. Uniaxial measurements were typically at peak stress levels, about $1 \mathrm{GPa}$, about two orders of magnitude less than the peak pressure levels in hydrostatic measurements, about $100 \mathrm{GPa}$, in which nonlinear effects are still small [34]. The single observation in one uniaxial study might have exhibited nonlinearity, but the small stress level, $0.4 \mathrm{GPa}$, suggests it was probably due to fixture compliance; the observation is unverified. Again, on a practical note, the information in Table 2 states that the numerical proportionality relationships for energy shift in an unconstrained single-crystal $c$ axis fiber under uniaxial stress are $\sigma_{\mathrm{u}}=\Delta v_{\sigma}^{(1)} / 1.6$ and $\sigma_{\mathrm{u}}=\Delta v_{\sigma}^{(2)} / 2.3$.

\subsubsection{Shock Tests}

The values in Tables 1 and 2 were obtained from quasi-static tests. Values obtained from rapid, shockloading tests by Gupta, Sharma, and colleagues agree with those in Tables 1 and 2, but some care is required in comparisons. First, although cast as uniaxial tests, the shock tests had mixed loading, i.e., neither uniaxial nor hydrostatic. The samples were $c$ - or $a$-oriented single crystals, with much of the loading ( $\sigma_{33}$ in the laboratory frame) more than $10 \mathrm{GPa}$, generating substantial $\sigma_{11}^{*}$ or $\sigma_{33}^{*}$ longitudinal stresses, respectively $[150,151]$. However, the shock-loading geometry also generated substantial simultaneous lateral stresses ( $\sigma_{11}$ and $\sigma_{22}$ ) - up to $24 \%$ of the longitudinal stress in the case of the $c$ crystal [151] (generating similarly large $\sigma_{11}^{*}$ and $\sigma_{22}^{*}$ ) and up to $77 \%$ in the case of the $a$ crystal [150] (large $\sigma_{22}^{*}$ and $\sigma_{33}^{*}$ ). A nonlinear third-order stress analysis was used to calculate the stress values [150]; the stress analysis was unverified. Second, comparisons between the quasi-static and shock experiments were made by calculating the change in energies of the $\mathrm{R}$ lines as a function of relative volume change (dilatational strain) under hydrostatic and shock loads using a nonlinear (Murnaghan), but isotropic, bulk modulus; the volume or density change using this nonlinear modulus assumption was unverified. Consistency with the referenced $7.6 \mathrm{~cm}^{-1} / \mathrm{GPa}$ hydrostatic pressure sensitivity [135] was shown, almost ideally so in the case of the $a$ crystal, which had a greater hydrostatic component, but no uncertainty measure was provided for the data. The origin of the slight nonlinearity observed in some of the data is unknown given the unverified analysis methods. 


\subsubsection{Fiber Tests}

True uniaxial tensile measurements (up to $0.8 \mathrm{GPa}$ ) were performed in early experiments by Liu et al. [79] on a free fiber stated to be single crystal, but which contained twins with $c$ axes at an angle of $20^{\circ}$ to $30^{\circ}$ to the fiber axis (and thus $\sigma_{33}^{*}$ was similarly misaligned with the applied stress $\sigma_{33}$ ). Values in the laboratory 3-direction of $\Pi_{\text {twinned }}^{(1)} \approx 1.7 \mathrm{~cm}^{-1} / \mathrm{GPa}$ and $\Pi_{\text {twinned }}^{(2)} \approx 2.3 \mathrm{~cm}^{-1} / \mathrm{GPa}$ were demonstrated, and consistency was claimed with the published values of Feher and Sturge [148]. (The fiber values were in fact more consistent with the smaller-value independent data fits to Ref. [148]; see Table 2.) Tests (up to 1.7 GPa) on single-crystal sapphire filaments bound in an epoxy matrix with the crystal $c$-axis aligned with the filament axis gave $\Pi_{c}^{(1)}=1.31 \mathrm{~cm}^{-1} / \mathrm{GPa}$ and $\Pi_{\mathrm{c}}^{(2)}=1.90 \mathrm{~cm}^{-1} / \mathrm{GPa}$ [86, 91], which are somewhat smaller than the consensus values (Table 2). Subsequent tests [89] on single-crystal fibers under uniaxial tension and compression (3-tensile axis aligned with $c$ axis, stress magnitude up to $0.55 \mathrm{GPa}$ ) gave a $\mathrm{R}_{2}$ shift of $877 \mathrm{~cm}^{-1} /$ strain $\pm 82 \mathrm{~cm}^{-1} /$ strain, which, in concert with the Young's modulus of $411 \mathrm{GPa} \pm 24$ GPa, produced $\Pi_{c}^{(2)}=2.13 \mathrm{~cm}^{-1} / \mathrm{GPa} \pm 0.23 \mathrm{~cm}^{-1} / \mathrm{GPa}$, a value more consistent with the consensus value (Table 2).

Experimental measurements on free $80 \mathrm{Al}_{2} \mathrm{O}_{3}-20 \mathrm{ZrO}_{2}$ polycrystalline composite fibers under uniaxial tension (up to $1.8 \mathrm{GPa}$ ) were reported by Yang and Young [82, 83]. These measurements gave sensitivities of $610 \mathrm{~cm}^{-1} /$ strain and $700 \mathrm{~cm}^{-1} /$ strain for $\mathrm{R}_{1}$ and $\mathrm{R}_{2}$, respectively, which, combined with the Young's modulus of $254 \mathrm{GPa}$, give $\Pi_{\text {poly }}^{(1)}=2.4 \mathrm{~cm}^{-1} / \mathrm{GPa}$ and $\Pi_{\text {poly }}^{(2)}=2.8 \mathrm{~cm}^{-1} / \mathrm{GPa}$. These values, as noted by the authors, are consistent with the predicted random polycrystalline response under uniaxial loading of (7.6/3) $\mathrm{cm}^{-1} / \mathrm{GPa}=2.5 \mathrm{~cm}^{-1} / \mathrm{GPa}$ from Eq. (12). Measurements in which an $80 \mathrm{Al}_{2} \mathrm{O}_{3}-20 \mathrm{ZrO}_{2}$ fiber was fixed to a (presumably constraining) substrate [84] gave $2.9 \mathrm{~cm}^{-1} / \mathrm{GPa}$.

Measurements on a polycrystalline, single-phase $\alpha-\mathrm{Al}_{2} \mathrm{O}_{3}$ fiber fixed to a substrate gave 1330 $\mathrm{cm}^{-1} /$ strain, and using the greater Young's modulus value of $380 \mathrm{GPa}$ gave a (probably constrained) value of $\Pi_{\text {poly }}^{(2)}=3.5 \mathrm{~cm}^{-1} / \mathrm{GPa}$ [87]. Uniaxial tensile measurements on a (presumably free, but constraint unstated) similar polycrystalline $\alpha-\mathrm{Al}_{2} \mathrm{O}_{3}$ fiber gave $\Pi_{\text {poly }}^{(2)}=2.53 \mathrm{~cm}^{-1} / \mathrm{GPa}$, noted to be consistent with the predicted polycrystalline response under uniaxial loading; see previous paragraph and Eq. (12) [88]. Uniaxial tension and compression tests [89] on a polycrystalline $\alpha-\mathrm{Al}_{2} \mathrm{O}_{3}$ fiber gave a $\mathrm{R}_{2}$ shift of $1178 \mathrm{~cm}^{-1} / \mathrm{strain} \pm 54$ $\mathrm{cm}^{-1} /$ strain, and using a modulus of $375 \mathrm{GPa} \pm 5 \mathrm{GPa}$ gave $\Pi_{\text {poly }}^{(2)}=3.14 \mathrm{~cm}^{-1} / \mathrm{GPa} \pm 0.14 \mathrm{~cm}^{-1} / \mathrm{GPa}$, which is larger than the predicted polycrystalline response. Similar tests (up to $2 \mathrm{GPa}$ ) on a similar fiber [90] gave $799 \mathrm{~cm}^{-1} /$ strain and $757 \mathrm{~cm}^{-1} /$ strain for $\mathrm{R}_{1}$ and $\mathrm{R}_{2}$, respectively, which, using the (manufacture) cited modulus of $260 \mathrm{GPa}$, give $\Pi_{\text {poly }}^{(1)}=3.07 \mathrm{~cm}^{-1} / \mathrm{GPa}$ and $\Pi_{\text {poly }}^{(2)}=2.91 \mathrm{~cm}^{-1} / \mathrm{GPa}$, which are larger than the predicted polycrystalline response.

In many fiber tests [79, 82, 83, 86, 90, 91], extensive data were provided to characterize the shift in the fluorescence energy with applied stress or strain. The stress or strain were extremely simple to determine given the extremely simple (fiber) geometry; in the case of uniaxial strain measurements, the conjugate uniaxial stress was easily calculated via a simple, linear plane-stress Young's modulus. Hence, the linear variation of shift with applied stress (up to a few gigapascals) is well verified by many observations with no caveats. The numerical agreement with the nonfiber coefficient determinations surveyed above further supports the observations.

\subsubsection{Bulk Polycrystal Tests}

There appear to be very few experimental measurements of piezospectroscopic effects in bulk polycrystals under uniaxial loading. Molis and Clarke [42] measured the $\mathrm{R}_{1}$ fluorescence energy shifts, importantly in compression and tension, in a polycrystalline beam in bending experiments (stress range $\pm 0.17 \mathrm{GPa}$ ), obtaining $\Pi_{\text {poly }}^{(1)}=2.4 \mathrm{~cm}^{-1} / \mathrm{GPa} \pm 0.1 \mathrm{~cm}^{-1} / \mathrm{GPa}$. Similar bending experiments (stress range $\pm 0.25 \mathrm{GPa}$ ) on a polycrystalline material were performed by Ma and Clarke [43], obtaining $\Pi_{\text {poly }}^{(1)}=2.46$ $\mathrm{cm}^{-1} / \mathrm{GPa}$ and $\Pi_{\text {poly }}^{(2)}=2.50 \mathrm{~cm}^{-1} / \mathrm{GPa}$. Extending their fiber experiments, Dassios and Galiotis [90] tested 
bulk polycrystals under uniaxial compression (stress to $-0.15 \mathrm{GPa}$ ) and obtained $\Pi_{\text {poly }}^{(1)}=2.57 \mathrm{~cm}^{-1} / \mathrm{GPa} \pm$ $0.03 \mathrm{~cm}^{-1} / \mathrm{GPa}$ and $\Pi_{\text {poly }}^{(2)}=2.52 \mathrm{~cm}^{-1} / \mathrm{GPa} \pm 0.03 \mathrm{~cm}^{-1} / \mathrm{GPa}$. Margueron and Clarke [115] tested thin-film polycrystals under uniaxial tension and compression (stress range $\pm 4 \mathrm{GPa}$, later changed to $-8 \mathrm{GPa}$ to 0 GPa [58]) and obtained $\Pi_{\text {poly }}^{(2)}=2.50 \mathrm{~cm}^{-1} / \mathrm{GPa} \pm 0.03 \mathrm{~cm}^{-1} / \mathrm{GPa}$. The $\mathrm{R}_{1}$ data were similar but exhibited slightly different coefficients in tension and compression. The observation (especially the strain gauge measurements) was unverified. All the above measurements agree with the polycrystalline prediction for uniaxial loading of $2.5 \mathrm{~cm}^{-1} / \mathrm{GPa}$ from Eq. (12). As with the fiber tests, extensive data were provided for the polycrystals to characterize the shift in fluorescence energy with stress or strain, where the stress or strain were extremely simple to determine given the simple (bending or compression) geometries, and the stress was easily calculated from strain via a Young's modulus. Hence, the linear variation of shift with applied stress (up to a few hundred megapascals; one unverified exception) and the numerical agreement with the non-polycrystal coefficient determinations surveyed above further support the observations. It is noted that the applied stress range of the polycrystal experiments was about an order of magnitude less than the single-crystal or fiber experiments (previous sections) and comparable to the intrinsic microstructural stresses expected and observed in bulk polycrystals [38-42, 58-67].

\subsection{Temperature}

Table 3 gives the first author, year published, citation, $\mathrm{R}$-line coefficients $\left(\mathrm{R}_{1}\right.$ or $\left.\mathrm{R}_{2}\right)$, and notes for original works that (experimentally) determined the temperature coefficients $\beta_{T}^{(1)}$ and $\beta_{T}^{(2)}$; see Eq. (13). Where necessary, the coefficients have been converted to a common set of units $\left(\mathrm{cm}^{-1} / \mathrm{K}\right)$. A dash in Table 3 indicates a coefficient was not specified. Where not given, uncertainties were not specified. Uncertainties in parentheses $( \pm x)$ represent an estimate based on information given in the publication. Otherwise, unless noted, uncertainties are those specified in the publication and represent standard deviations of the mean of experimental measurements.

A striking feature of Table 3 is that agreement regarding the value of the temperature coefficient of the R-line shifts in alumina (at $300 \mathrm{~K}$ ) was achieved from the beginning: Most reported observations fall in the range $\beta_{T}^{(1)}=\beta_{T}^{(2)}=(-0.140 \pm 0.007) \mathrm{cm}^{-1} / \mathrm{K}$, with no meaningful distinction between the behavior of $\mathrm{R}_{1}$ and $\mathrm{R}_{2}$ or meaningful historical variation. (The values quoted here are representative of the historical variability and are not the result of statistical calculation.)

\subsection{Composition}

There are extremely few reports of the effects of variations in the (dilute) Cr concentration on the energy shifts of the R lines in alumina or ruby. Dilute alumina or rubies are those in which isolated Cr ions do not interact quantum mechanically, but simply mechanically through the increased ionic volume of $\mathrm{Cr}^{3+}$ relative to $\mathrm{Al}^{3+}[1,2,44]$. Early (and later) work showed that $\mathrm{Cr}$ ion pair interactions were very important in the optical properties of (heavily doped) ruby [61, 157-161], but such interactions are excluded here in consideration of piezospectroscopic effects in dilute ruby. Table 4 gives the first author, year published, citation, $\mathrm{R}$-line coefficients $\left(\mathrm{R}_{1}\right.$ or $\mathrm{R}_{2}$ ), and notes for original works that (experimentally) determined the composition coefficients $\beta_{C}^{(1)}$ and $\beta_{C}^{(2)}$; see Eq. (14). Where necessary, the coefficients have been converted to a common set of units $\left(\mathrm{cm}^{-1} /\right.$ mass fraction $\left.\mathrm{Cr}\right)$. A dash in Table 4 indicates a coefficient was not specified. Where not given, uncertainties were not specified. Uncertainties in parentheses $( \pm x)$ represent an estimate based on information given in the publication. Otherwise, unless otherwise noted, uncertainties are those specified in the publication and represent standard deviations of the mean of experimental measurements. 
Table 3. Temperature coefficients ${ }^{\mathrm{a}}$ for R-line shifts in alumina.

\begin{tabular}{|c|c|c|c|}
\hline Author & $\begin{array}{l}\text { Coefficient, } \\
\beta_{T}^{(1)}\left(\mathrm{cm}^{-1} / \mathrm{K}\right)\end{array}$ & $\begin{array}{l}\text { Coefficient, } \\
\beta_{T}^{(2)}\left(\mathrm{cm}^{-1} / \mathrm{K}\right)\end{array}$ & Notes \\
\hline Paetzold, 1951 [142] & -0.139 & -0.141 & $290 \mathrm{~K}$ \\
\hline McCumber, 1963 [152] & $-0.14( \pm 0.02)$ & $-0.14( \pm 0.02)$ & interpolated from graph \\
\hline Powell, 1966 [153] & $-0.12( \pm 0.02)$ & $-0.12( \pm 0.02)$ & interpolated from graph \\
\hline Barnett, 1973 [17] & $-0.14( \pm 0.07)$ & $-0.14( \pm 0.07)$ & “accurate to approximately $10 \%$ " \\
\hline Yamaoka, 1980 [37] & -0.14 & - & as cited by Ref. [29] \\
\hline Wunder, 1981 [23] & -0.1487 & - & “confidence level of >99 \%” \\
\hline Munro, 1985 [135] & $-0.130 \pm 0.006$ & $-0.122 \pm 0.006$ & “99 \% confidence level” \\
\hline Vos, 1991; Rekhi, 1999 [28, 32] & $-0.136( \pm 0.005)$ & $-0.136( \pm 0.005)$ & from $R_{1}, R_{2}$ average fit equation; interpolated from graphs \\
\hline Yen, 1992 [154] & -0.153 & - & interpolated from graph \\
\hline Ragan, 1992 [155] & -0.158 & -0.162 & linear approximation \\
\hline Fujishiro, 1994 [29] & -0.133 & - & \\
\hline Huang, 1994 [156] & $-0.140( \pm 0.007)$ & $-0.140( \pm 0.007)$ & interpolated from graph \\
\hline He, 1995 [45] & -0.144 & -0.134 & \\
\hline Young, 1996 [83] & -0.167 & - & interpolated from graph; composite fiber \\
\hline Gibson, 1999 [141] & $-0.133( \pm 0.007)$ & $-0.145( \pm 0.007)$ & interpolated from graph \\
\hline Grasset, 2001 [136] & $-0.140 \pm 0.05$ & $-0.137 \pm 0.05$ & $95 \%$ confidence interval \\
\hline Kumari, 2011 [95] & -0.133 & -0.133 & interpolated from graph and empirical equation \\
\hline Gao, 2015 [57] & $-0.1519 \pm 0.0008$ & $\begin{array}{c}-0.1522 \pm \\
0.0014\end{array}$ & $0.556 \%$ mass fraction of $\mathrm{Cr}$ sample \\
\hline
\end{tabular}

${ }^{\mathrm{a}}$ All measurements were at approximately $300 \mathrm{~K}$.

Table 4. Composition coefficients ${ }^{\mathrm{a}}$ for R-line shifts in alumina.

\begin{tabular}{|c|c|c|c|}
\hline Author & $\begin{array}{c}\text { Coefficient, } \\
\beta_{C}^{(1)}\left(\mathrm{cm}^{-1} / \mathrm{mass}\right. \\
\text { fraction })\end{array}$ & $\begin{array}{c}\text { Coefficient, } \\
\beta_{C}^{(2)}\left(\mathrm{cm}^{-1} / \mathrm{mass}\right. \\
\text { fraction })\end{array}$ & Notes \\
\hline Kaplyanskii, 1969 [139] & $96 \pm 5$ & $101 \pm 5$ & $77 \mathrm{~K}$ \\
\hline Yu, 2002 [50] & - & 82.7 and 136.4 & $\mathrm{RT}^{\mathrm{b}}$ and $77 \mathrm{~K}$ \\
\hline Gao, 2015 [57] & $156( \pm 50)$ & $92( \pm 20)$ & RT, estimated from graph \\
\hline Michaels, 2016 [67] & $160( \pm 2)$ & $167( \pm 3)$ & RT \\
\hline Margueron, 2017 [162] & 100 & 100 & \\
\hline
\end{tabular}

${ }^{a}$ All values in $\mathrm{cm}^{-1} /$ mass fraction of $\mathrm{Cr}$ in $\mathrm{Al}_{2} \mathrm{O}_{3}$ (i.e., $100 \times$ "wt \%" of $\mathrm{Cr}$ in $\mathrm{Al}_{2} \mathrm{O}_{3}: \mathrm{Cr}$ [66]).

${ }^{\mathrm{b}} \mathrm{RT}$ indicates room temperature.

Despite the few reported values (and caveats regarding the interfering effects of co-doping [50, 57]), a valid estimation (not a formal mean) seems to be $\beta_{C}^{(1)}=\beta_{C}^{(2)} \approx(120 \pm 30) \mathrm{cm}^{-1} /$ mass fraction, with no meaningful distinction between the behavior of $R_{1}$ and $R_{2}$ or meaningful historical variation. (The values quoted here are representative of the historical variability and are not the result of statistical calculation.) Within the experimental scatter, the separability of composition and temperature effects holds (i.e., $\beta_{C}$ and $\beta_{T}$ are independent).

\section{Discussion}

Perhaps the most striking feature of the fluorescence energy coefficients cited above is the historical consistency of the values, particularly those coefficients relating fluorescence energy changes to variations in pressure (Table 1) and temperature (Table 3). Extending over a 40 year period, most pressure coefficient measurements fell within a $1 \%$ relative variation, and over a 60 year period, most temperature coefficient 
measurements fell within a $0.5 \%$ relative variation. There are probably several (unsurprising and interrelated) reasons for this consistency: First, both pressure and temperature are scalars, and thus formulations relating fluorescence energy shifts to pressure and temperature, both experimentally and theoretically, are relatively simple. Second, pressure and temperature are fundamental thermodynamic parameters, and thus the experimental infrastructure is well established (e.g., instrumented DACs) for measuring their effects. Third, the historical consistency probably reflects an example of "convergent publication," in which values are reported only if they are consistent with previously published values. Notwithstanding the potential absence of some results and the often absence of uncertainties, the coefficients determining pressure and temperature effects (in the linear range) on fluorescence energies in alumina are accurate and precise.

The simplest meanings of the pressure and temperature coefficients are embodied in their units. A 1 $\mathrm{cm}^{-1}$ of energy shift in the R-lines will be caused by $132 \mathrm{MPa}\left(0.132 \mathrm{GPa}=1 \mathrm{~cm}^{-1} /\left[7.6 \mathrm{~cm}^{-1} / \mathrm{GPa}\right]\right)$ of equitriaxial stress (hydrostatic pressure when negative or compressive); see Eq. (5) and Table 1. This is a very small pressure for a DAC, and the energy shift is modest (with adequate sampling, this shift is easily detected, e.g., Ref. [67, 135]; for an $\mathrm{R}_{1}$ shift of $14403 \mathrm{~cm}^{-1}$ to $14402 \mathrm{~cm}^{-1}$, this corresponds to a wavelength increase from $694.30 \mathrm{~nm}$ to $694.35 \mathrm{~nm}$ ). A $1 \mathrm{~cm}^{-1}$ energy shift will also be caused by about $7 \mathrm{~K}$ of temperature excursion $\left(7.1 \mathrm{~K}=1 \mathrm{~cm}^{-1} /\left[0.140 \mathrm{~cm}^{-1} / \mathrm{K}\right]\right.$; again, easily applied and measured); see Eq. (13) and Table 3. To place these effects in atomic-scale context, it should be realized that $132 \mathrm{MPa}$ of equitriaxial stress corresponds to a volume strain of $5.2 \times 10^{-4}$ (using a linear bulk modulus of $253 \mathrm{GPa}$ [2]). That is, to first approximation, the volume of the $\mathrm{O}^{2-}$ octahedron surrounding the substitutional $\mathrm{Cr}^{3+}$ ion undergoes a relative volume change of $5.2 \times 10^{-4}$, and the $\mathrm{O}^{2-}-\mathrm{Cr}^{3+}$ separation undergoes a relative length change of about 0.08 : The spectroscopic effects of stress are large because the changes to the crystal field (as quantified by the ionic separation) are large. A similar approximation leading to a similar conclusion can be made using the volume thermal expansion coefficient (about $17 \times 10^{-6} \mathrm{~K}^{-1}$ [163]), resulting in a relative ionic separation change of about 0.05 for a temperature change of $7 \mathrm{~K}$.

Historical and between-laboratory consistency is slightly weak in the case of coefficients relating fluorescence energy changes to changes in the tensor stress field (Table 2) and to changes in composition (Table 4): Most stress tensor component measurements fell within a $4 \%$ relative variation, and the composition coefficient measurements exhibited a $25 \%$ relative variation. In both cases, there is a limited sample set, so it is difficult to draw definitive conclusions regarding accuracy and precision. Ma and Clarke [44] argued that the value of the coefficient relating energy shift to composition in Table 4 is about right (it is accurate). They cited an explicit measurement of density variation with composition to arrive at a dilatational strain that was used in a mechanics analysis for positive comparison with pressure experiments (in a similar use of relative volume to compare experiments as in the shock work [150,151]). A $1 \mathrm{~cm}^{-1}$ energy shift will be caused by changes in composition of about 0.008 mass fraction of $\mathrm{Cr}$ in $\mathrm{Al}_{2} \mathrm{O}_{3}: \mathrm{Cr}$ $\left(0.008=1 \mathrm{~cm}^{-1} /\left[120 \mathrm{~cm}^{-1]} /\right.\right.$ mass fraction); see Eq. (14) and Table 4 . This composition, about 0.002 substitution of $\mathrm{Cr}^{3+}$ for $\mathrm{Al}^{3+}$, is too small, even given the ionic radius increase (see Introduction), to generate the octahedral dilatations inferred for pressure and temperature effects and yet begins to approach that of "heavily doped" ruby, in which $\mathrm{Cr}^{3+}-\mathrm{Cr}^{3+}$ pair-wise interaction effects cannot be ignored [160]. Clearly, more research is required on the composition coefficient. (The gross variations in emission color and intensity with $\mathrm{Cr}$ composition were noted in the very earliest—1850s-observations of $\mathrm{Al}_{2} \mathrm{O}_{3}: \mathrm{Cr}$ luminescence [164].)

A constraint is placed on the components of the piezospectroscopic tensor $\Pi_{i j}$, in that the trace of this tensor must yield the piezospectroscopic pressure coefficient from Eqs. (4) and (5). However, in only two cases (Table 2) have the sums $\Pi_{a}^{(x)}+\Pi_{m}^{(x)}+\Pi_{c}^{(x)}[45]$ or $2 \Pi_{a}^{(x)}+\Pi_{c}^{(x)}[146]$ been checked to show agreement with the known values of $\Pi_{p}^{(x)}$, and in both cases, uncertainties in the components were not given, so the significance is difficult to judge. In both cases in which $\Pi_{m}^{(x)}$ was measured separately from $\Pi_{a}^{(x)}[45,148]$, subsequent digitization and fitting to estimate uncertainties (in the work here) led to different estimates for the mean coefficients, further confusing the significance of the results. Nevertheless, the mean and constrained value estimates (Table 2) for both the individual coefficients and their sums have accuracies comparable to their precisions. (Some works have mis-cited other works, leading to more 
confusion. For example: Langer [143] and Forman [16] incorrectly cited Paetzold [142] as $\Pi_{a}^{(1)}=9.5$ and $\Pi_{a}^{(2)}=8.4$ and $\Pi_{a}^{(1)}=9.3$ and $\Pi_{a}^{(2)}=8.2$, respectively; Grabner [38], Molis [42], and He [45] incorrectly cited Schawlow [140] for $\Pi_{a}^{(x)}, \Pi_{c}^{(x)}$, and $\Pi_{p}^{(x)}$ values, when no values were provided; Grabner [38] incorrectly cited Kaplyanskii [146] as $\Pi_{a}^{(1)}=3.2, \Pi_{p}^{(1)}=7.8, \Pi_{a}^{(2)}=2.8$, and $\Pi_{p}^{(2)}=7.5$; Ma [58] incorrectly cited Kaplyanskii [158] for $\Pi$ values, when no values were provided; He [45] incorrectly cited Kaplyanskii [146] as $\Pi_{a}^{(1)}=3.2$ and $\Pi_{a}^{(2)}=2.8$; and Ma [43] and He [45] incorrectly cited Feher [148] as $\Pi_{a}^{(1)}=2.7$, $\Pi_{c}^{(1)}=1.8, \Pi_{a}^{(2)}=2.4$, and $\Pi_{c}^{(2)}=2.2$. Other works cited values "to be published" that never appeared, e.g., Ref. [59]. The above works should not be cited in support of coefficient values.)

Some tests of apparently uniaxial geometry were in fact tests of single-crystal- or polycrystalorientation averaging rather than tests of individual tensor coefficients. It should be noted that the undifferentiated sum $2 \Pi_{a}^{(x)}+\Pi_{c}^{(x)}$ appears as the single-crystal pressure coefficient in Eq. (5), averaging over all single-crystal loading orientations, and as the polycrystal coefficient in Eq. (12), averaging over all arbitrarily loaded polycrystal grain orientations. The shock tests $[150,151]$ make explicit comparison with the single-crystal pressure tests. Fiber measurements were compared with the predicted polycrystalline average values, e.g., Refs. [82, 88], as were the uniaxial or bending polycrystal measurements [42, 43, 90]. These tests were good measures of the sum (which is well known; Table 1), but could not distinguish individual piezospectroscopic components. Similar limited conclusions can be made regarding biaxial tests and comparison with the polycrystalline prediction [100].

A major goal of this review is to assess the state of fluorescence piezospectroscopic coefficients for use in measuring and mapping stress distributions in bulk polycrystalline alumina. In addition to considering the historical context of the coefficients and the likely accuracy and precision as above, it is worth considering the relative sizes of the effects of stress, temperature, and composition in a typical fluorescence measurement. Incorporating temperature and composition coefficients explicitly into Eq. (1a) gives

$$
\Delta v_{\sigma}=\Delta v-\beta_{T}\left(T-T_{\text {ref }}\right)-\beta_{C} C .
$$

Assuming that a reference experiment is conducted on a (typically sapphire) specimen of known stress state (zero), temperature (adjusted to a reference point, often $298.8 \mathrm{~K}$ ), and composition (near zero Cr), the net fluorescence shift $\Delta v$ for the target alumina is easily determined (as $v_{0}$ is now well known). Typical large values are $\Delta v^{(1)}=-0.80 \mathrm{~cm}^{-1}$ and $\Delta v^{(2)}=-0.60 \mathrm{~cm}^{-1}$ [67]. A typical value for $T$ is $21{ }^{\circ} \mathrm{C}=294.15 \mathrm{~K}$. A typical value for $C$ for alumina is 0.0001 . Equation (1 $\left.1 a^{\prime}\right)$ thus becomes (using Tables 3 and 4 )

$$
\begin{aligned}
& \Delta v_{\sigma}^{(1)}=-0.80-(-0.14)(-4.65)-(120)(0.0001)=-0.80-0.65-0.01=-1.46 \mathrm{~cm}^{-1}, \\
& \Delta v_{\sigma}^{(2)}=-0.60-(-0.14)(-4.65)-(120)(0.0001)=-0.60-0.65-0.01=-1.26 \mathrm{~cm}^{-1}
\end{aligned}
$$

Two features are apparent in the above calculations: Temperature effects (the second terms in the third equalities) are large comparable to the overall stress effect, and composition effects (the third terms) are small, probably negligible. Even a range of net shifts (as is observed in Ref. [67], $\pm 0.8 \mathrm{~cm}^{-1}$, reflecting a range of stress states and peak shifts) does not alter these conclusions.

Continuing on to typical calculations for a polycrystal: Using the constrained values in Table 2 and Eq. (10) yields $\Pi_{\mathrm{M}}^{(1)}=\Pi_{\mathrm{M}}^{(2)}=7.60 \mathrm{~cm}^{-1} / \mathrm{GPa}, \Pi_{\mathrm{S}}^{(1)}=-1.34 \mathrm{~cm}^{-1} / \mathrm{GPa}$, and $\Pi_{\mathrm{S}}^{(2)}=-0.32 \mathrm{~cm}^{-1} / \mathrm{GPa}$. In combination with typical values of $\Delta v_{\sigma}^{(1)}=-1.46 \mathrm{~cm}^{-1}$ and $\Delta v_{\sigma}^{(2)}=-1.26 \mathrm{~cm}^{-1}$ measured at a single point in a polycrystal as above, Eq. (11) leads to $\sigma_{\mathrm{M}}=-158 \mathrm{MPa}$ and $\sigma_{\mathrm{S}}=196 \mathrm{MPa}$. If $\Delta v=-1.46 \mathrm{~cm}^{-1}$ represents the shift averaged over many points in a random polycrystal under uniaxial stress, then Eq. (12) leads to $\sigma_{\mathrm{u}}=-1.46 /(7.6 / 3)=-577 \mathrm{MPa}$.

For a thermally grown oxide random polycrystal film under biaxial stress, the stress levels of many gigapascals lead to fluorescence energy shifts of many wavenumbers [96-119], and the temperature and composition "corrections" above are unnecessary. Similarly, unless there is a comparison of results from different measurement methods, e.g., between shock and static pressure [150], or with a model, e.g., Ref. 
[58], temperature and composition corrections are not necessary. In these cases, relative measurements are adequate, as shown by the large number of application works cited in the Introduction (about 70) compared with the smaller number of calibration works cited in the Results (about 30). The large stresses observed in many thermally grown oxide films suggest that nonlinear effects might be important in these systems (similar to those observed in Fig. 5). Using a refined crystal field model calibrated to the known nonlinear observations [45, 115, 150, 151], Margueron and Clarke [58] suggested a quadratic fit for the polycrystalline $\mathrm{R}_{2}$ line shift under hydrostatic pressure of about $\Delta v_{p}^{(2)}=-7.62 p-0.0046 p^{2}$, where the pressure $p$ has units of GPa. For a pressure of $2 \mathrm{GPa}$, the quadratic contribution to the shift is about 0.02 $\mathrm{cm}^{-1}$. As a correction to an estimate of stress, this value is negligible relative to the shifts considered above. When treated as an uncertainty, however, this value is about twice the uncertainty associated with line position. However, as shown below, both are small (but not negligible) relative to temperature effects. Raman spectroscopy, electron backscatter diffraction, and X-ray diffraction [138] could all be used on thermally grown oxide films to independently calibrate nonlinear effects.

For a bulk polycrystal, not only are the corrections necessary, but the uncertainties in the quantities on the right side of Eq. (1a) must be considered. Assuming that the positions of either peak of the $\mathrm{R}_{1}$ and $\mathrm{R}_{2}$ fluorescence lines can be determined with an experimental uncertainty of $u\left(\Delta v^{(x)}\right)=0.01 \mathrm{~cm}^{-1}$ [67], and using the information in Tables 3 and 4, the uncertainty in the stress-related shift, $u\left(\Delta v_{\sigma}\right)$, is given by summing the absolute uncertainties in quadrature [165], taking $u\left(\beta_{T}\right)=0.007 \mathrm{~cm}^{-1} / \mathrm{K}$ and $u\left(\beta_{T}\right)=30$ $\mathrm{cm}^{-1} /$ mass fraction,

$$
\begin{aligned}
u\left(\Delta v_{\sigma}\right) & =\left[u^{2}(\Delta v)+\left(u\left(\beta_{T}\right) * 4.65\right)^{2}+\left(u\left(\beta_{C}\right) * 0.0001\right)^{2}\right]^{1 / 2} \\
& \approx\left[10^{-4}+10^{-3}+10^{-5}\right]^{1 / 2}=0.035 \mathrm{~cm}^{-1}
\end{aligned}
$$

The second line of this equation has been written to make clear that the greatest contribution to the uncertainty in the stress shift is the uncertainty in the temperature coefficient (the middle term). Temperature corrections are a necessity for accurate and precise stress determinations by fluorescence shifts. Nevertheless, the relative uncertainty in the stress shift is only $(0.035 / 1.46) \approx 2.3 \%$, and Table 2 and Eq. (11) show that this term dominates the uncertainty in the stress calculation. Hence, the uncertainty in $\sigma_{\mathrm{M}}=-158 \mathrm{MPa}$ calculated above is $u\left(\sigma_{\mathrm{M}}\right) \approx 4 \mathrm{MPa}$ (given exactly by summing all the relative uncertainties in quadrature [165]). The stress uncertainty is small, making clear why the fluorescence method is effective for estimating stress and stress distributions [43, 59, 66, 67] in bulk polycrystalline alumina.

\section{Acknowledgments}

The authors thank Drs. Y. B. Gerbig and D. L. Kaiser, both of National Institute of Standards and Technology (NIST), and Dr. S. Margueron of Université de Lorraine et Centrale Supélec, for careful review of the manuscript.

\section{References}

[1] Burns R (2005) Mineralogical Applications of Crystal Fie1d Theory (Cambridge University Press, Cambridge), 2nd Ed.

[2] Syassen K (2008) Ruby under pressure. High Pressure Research 28(2):75-126. https://doi.org/10.1080/08957950802235640.

[3] Moss S, Newnham R (1964) The chromium position in ruby. Zeitschrift für Kristallographie 120(4-5):359-363. https://doi.org/10.1524/zkri.1964.120.4-5.359.

[4] Brown G Jr (1964) Fluorescence lifetimes of ruby. Journal of Applied Physics 35:3062-3063. https://doi.org/10.1063/1.1713175.

[5] Tanabe Y, Sugano S (1954) On the absorption spectra of complex ions. I. Journal of the Physical Society of Japan 9(5):753766. https://doi.org/10.1143/JPSJ.9.753.

[6] Tanabe Y, Sugano S (1954) On the absorption spectra of complex ion. II. Journal of the Physical Society of Japan 9(5):766-779. https://doi.org/10.1143/JPSJ.9.766.

[7] Tanabe Y, Sugano S (1956) On the absorption spectra of complex ions, III. The calculation of the crystal field strength. Journal of the Physical Society of Japan 11(8):864-877. https://doi.org/10.1143/JPSJ.11.864. 
[8] Tanabe Y, Kamimura H (1958) On the absorption spectra of complex ions, IV. The effect of the spin-orbit interaction and the field of lower symmetry on $d$ electrons in cubic field. Journal of the Physical Society of Japan 13(4):394-411. https://doi.org/10.1143/JPSJ.13.394.

[9] Sugano S, Tanabe, $\mathrm{Y}$ (1958) Absorption spectra of $\mathrm{Cr}^{3+} \mathrm{Al}_{2} \mathrm{O}_{3}$. Part A. Theoretical studies of the absorption bands and lines. Journal of the Physical Society of Japan 13(8):880-899. https://doi.org/10.1143/JPSJ.13.880.

[10] Sugano S, Tsujikawa I (1958) Absorption spectra of $\mathrm{Cr}^{3+} \mathrm{Al}_{2} \mathrm{O}_{3}$. Part B. Experimental studies of the Zeeman effect and other properties of the line spectra. Journal of the Physical Society of Japan 13(8):899-910. https://doi.org/10.1143/JPSJ.13.899.

[11] McClure D (1962) Optical spectra of transition-metal ions in corundum. Journal of Chemical Physics 36(10):2757-2779. https://doi.org/10.1063/1.1732364.

[12] Macfarlane R (1963) Analysis of the spectrum of $d^{3}$ ions in trigonal crystal fields. Journal of Chemical Physics 39(11):31183126. https://doi.org/10.1063/1.1734152.

[13] Poole C Jr (1964) The optical spectra and color of chromium containing solids. Journal of Physics and Chemistry of Solids 25(11):1169-1182. https://doi.org/10.1016/0022-3697(64)90014-9.

[14] Devlin G, McKenna J, May A, Schawlow A (1962) Composite rod optical masers. Applied Optics 1(1):11-15. https://doi.org/10.1364/AO.1.000011.

[15] Collins R, Nelson D, Schawlow A, Bond W, Garrett C, Kaiser W (1960) Coherence, narrowing, directionality, and relaxation oscillations in the light emissions from ruby. Physical Review Letters 5(7):303-305. https://doi.org/10.1103/PhysRevLett.5.303.

[16] Forman R, Piermarini G, Barnett J, Block S (1972) Pressure measurement made by the utilization of ruby sharp-line luminescence. Science 176(4032):284-285. https://doi.org/10.1126/science.176.4032.284.

[17] Barnett J, Block S, Piermarini G (1973) An optical fluorescence system for quantitative pressure measurement in the diamondanvil cell. Review of Scientific Instruments 44(1):1-9. https://doi.org/10.1063/1.1685943.

[18] Hawke R, Syassen K, Holzapfel W (1974) An apparatus for high pressure Raman spectroscopy. Review of Scientific Instruments 45(12):1598-1601. https://doi.org/10.1063/1.1686569.

[19] Piermarini G, Block S (1975) Ultrahigh pressure diamond-anvil cell and several semiconductor phase transition pressures in relation to the fixed point pressure scale. Review of Scientific Instruments 46(8):973-979. https://doi.org/10.1063/1.1134381.

[20] Piermarini G, Block S, Barnett J, Forman R (1975) Calibration of the pressure dependence of the $R_{1}$ ruby fluorescence line to 195 kbar. Journal of Applied Physics 46(6):2774-2780. https://doi.org/10.1063/1.321957.

[21] Adams D, Appleby R, Sharma S (1976) Spectroscopy at very high pressures: Part X. Use of ruby R-lines in the estimation of pressure at ambient and at low temperatures. Journal of Physics E: Scientific Instruments 9:1140-1144. https://doi.org/10.1088/0022-3735/9/12/034.

[22] Mao H, Bell P, Shaner J, Steinberg D (1978) Specific volume measurements of Cu, Mo, Pd, and Ag and calibration of the ruby $\mathrm{R}_{1}$ fluorescence pressure gauge from 0.06 to 1 Mbar. Journal of Applied Physics 49(6):3276-3283. https://doi.org/10.1063/1.325277.

[23] Wunder S, Schoen P (1981) Pressure measurement at high temperatures in the diamond anvil cell. Journal of Applied Physics 52(6):3772-3775. https://doi.org/10.1063/1.329841.

[24] Xu J, Mao H, Bell P (1986) High-pressure ruby and diamond fluorescence: observations at 0.21 to 0.55 Terapascal. Science 232(4756):1404-1406. https://doi.org/10.1126/science.232.4756.1404.

[25] Mao H, Xu J, Bell P (1986) Calibration of the ruby pressure gauge to 800 kbar under quasi-hydrostatic conditions. Journal of Geophysical Research 91(B5):4673-4676. https://doi.org/10.1029/JB091iB05p04673.

[26] Eggert J, Goettel K, Silvera I (1989) Ruby at high pressure. I. Optical line shifts to 156 GPa. Physical Review B 40(8):57245732. https://doi.org/10.1103/PhysRevB.40.5724.

[27] Eggert J, Goettel K, Silvera I (1989) Ruby at high pressure. II. Fluorescence lifetime of the $R$ line to 130 GPa. Physical Review $B$ 40(8):5733-5738. https://doi.org/10.1103/PhysRevB.40.5733.

[28] Vos W, Schouten J (1991) On the temperature correction to the ruby pressure scale. Journal of Applied Physics 69(9):67446746. https://doi.org/10.1063/1.348903.

[29] Fujishiro I, Nakamura Y, Yamanokuchi H (1994) Evaluation of temperature dependence on ruby fluorescence at high pressure by viscosity measurement of lubricants. AIP Conference Proceedings 309:1059-1062. https://doi.org/10.1063/1.46286.

[30] Chai M, Brown J (1996) Effects of static non-hydrostatic stress on the R lines of ruby single crystals. Geophysical Research Letters 23(24):3539-3542. https://doi.org/10.1029/96GL03372.

[31] Chen N, Silvera I (1996) Excitation of ruby fluorescence at multimegabar pressures. Review of Scientific Instruments 67(12):4275-4278. https://doi.org/10.1063/1.1147526.

[32] Rekhi R, Dubrovinsky L, Saxena S (1999) Temperature-induced ruby fluorescence shifts up to a pressure of 15 GPa in an externally heated diamond anvil cell. High Temperatures-High Pressures 31(3):299-305. https://doi.org/10.1068/htrt161.

[33] Holzapfel W (2003) Refinement of the ruby luminescence pressure scale. Journal of Applied Physics 93(3):1813-1818. https://doi.org/10.1063/1.1525856.

[34] Chijioke A, Nellis W, Soldatov A, Silvera I (2005) The ruby pressure standard to 150 GPa. Journal of Applied Physics 98:114905. https://doi.org/10.1063/1.2135877.

[35] Silvera I, Chijioke A, Nellis W, Soldatov A, Temper J (2007) Calibration of the ruby pressure scale to 150 GPa. Physica Status Solidi (b) 244(1):460-467. https://doi.org/10.1002/pssb.200672587.

[36] Goncharov A, Zaug J, Crowhurst J, Gregoryanz E (2005) Optical calibration of pressure sensors for high pressures and temperatures. Journal of Applied Physics (97):094917. https://doi.org/10.1063/1.1895467.

[37] Yamaoka H, Zekko Y, Jarrige I, Lin J, Hiraoka N, Ishii H, Tsuei K, Mizuki J (2012) Ruby pressure scale in a low-temperature diamond anvil cell. Journal of Applied Physics (112):124503. https://doi.org/10.1063/1.4769305.

[38] Grabner L (1978) Spectroscopic technique for the measurement of residual stress in sintered $\mathrm{Al}_{2} \mathrm{O}_{3}$. Journal of Applied Physics 49(2):580-583. https://doi.org/10.1063/1.324682.

[39] Blendell J, Coble R, Charles R (1976) On the relaxation of stresses arising from thermal expansion anisotropy during cooling polycrystalline materials. Ceramic Microstructures, ed. Fulrath RM, Pask JA (Westview Press, Boulder) pp 721-730. 
[40] Blendell J, Coble R (1982) Measurement of stress due to thermal expansion anisotropy in $\mathrm{Al}_{2} \mathrm{O}_{3}$. Journal of the American Ceramic Society 65(3):174-178. https://doi.org/10.1111/j.1151-2916.1982.tb10390.x.

[41] Song H, French R, Coble R (1989) Effect of residual strain on the electronic structure of alumina and magnesia. Journal of the American Ceramic Society 72(6):990-994. https://doi.org/10.1111/j.1151-2916.1989.tb06257.x.

[42] Molis S, Clarke D (1990) Measurement of stresses using fluorescence in an optical microprobe: Stresses around indentations in a chromium-doped sapphire. Journal of the American Ceramic Society 73(11):3189-3194. https://doi.org/10.1111/ j.1151-2916.1990.tb06435.x.

[43] Ma Q, Clarke D (1993) Stress measurement in single-crystal and polycrystalline ceramics using their optical fluorescence. Journal of the American Ceramic Society 76(6):1433-1440. https://doi.org/10.1111/j.1151-2916.1993.tb03922.x.

[44] Ma Q, Clarke D (1993) Optical fluorescence from chromium ions in sapphire: A probe of the image stress. Acta Metallurgica et Materialia 41(6):1811-1816. https://doi.org/10.1016/0956-7151(93)90201-3.

[45] He J, Clarke D (1995) Determination of the piezospectroscopic coefficients for chromium-doped sapphire. Journal of the American Ceramic Society 78(5):1347-1353. https://doi.org/10.1111/j.1151-2916.1995.tb08493.x.

[46] Lipkin D, Clarke D (1995) Sample-probe interactions in spectroscopy: Sampling microscopic property gradients. Journal of Applied Physics 77(5):1855-1863. https://doi.org/10.1063/1.358885.

[47] Kizler P, He J, Clarke D, Kenway P (1996) Structural relaxation around substitutional $\mathrm{Cr}^{3+}$ ions in sapphire. Journal of the American Ceramic Society 79(1):3-11. https://doi.org/10.1111/j.1151-2916.1996.tb07873.x.

[48] He J, Clarke D (1997) Polarization dependence of the $\mathrm{Cr}^{3+} \mathrm{R}$-line fluorescence from sapphire and its application to crystal orientation and piezospectroscopic measurement. Journal of the American Ceramic Society 79(1):3-11. https://doi.org/10.1111/j.1151-2916.1997.tb02792.x.

[49] Atkinson A, Jain S, Webb S (1999) Convolution of spectra in optical microprobe experiments. Semiconductor Science and Technology 14:561-564. https://doi.org/10.1088/0268-1242/14/6/312.

[50] Yu H, Clarke D (2002) Effect of codoping on the R-line luminescence of $\mathrm{Cr}^{3+}$-doped alumina. Journal of the American Ceramic Society 85(8):1966-1970. https://doi.org/10.1111/j.1151-2916.2002.tb00389.x.

[51] Wan K, Zhu W, Pezzotti G (2006) Methods of piezo-spectroscopic calibration of thin-film materials: I. Ball-on-ring biaxial flexure. Measurement Science and Technology 17(1):181-190. https://doi.org/10.1088/0957-0233/17/1/029.

[52] Zhu W, Wan K, Pezzotti G (2006) Methods of piezo-spectroscopic calibration of thin-film materials: II. Tensile stress field at indentation crack tip. Measurement Science and Technology 17(1):191-198. https://doi.org/10.1088/0957-0233/17/1/030.

[53] Margueron S, Clarke D (2007) Stress anisotropy of the R-line luminescence lifetime in single crystal Cr-doped sapphire (ruby). Journal of Applied Physics (101):093521. https://doi.org/10.1063/1.2727443.

[54] Margueron S, eClarke D (2007) Effect of polarization and uniaxial stress on the R-line luminescence of single crystal sapphire. Journal of Applied Physics (101):093902. https://doi.org/10.1063/1.2717155.

[55] Margueron S, Clarke D (2007) Effect of residual stress on the luminescence lifetime of R-line emission from polycrystalline alumina formed by oxidation. Journal of the American Ceramic Society 90(6):1798-1801. https://doi.org/10.1111/ j.1551-2916.2007.01635.x.

[56] Guo S, Todd R (2010) Confocal fluorescence microscopy in alumina-based ceramics: Where does the signal come from? Journal of the European Ceramic Society 30(3):641-648. https://doi.org/10.1016/j.jeurceramsoc.2009.08.020.

[57] Gao R, Li H, Zhao J (2015) Dependence of R fluorescence lines of rubies on $\mathrm{Cr}^{3+}$ concentration at various temperatures, with implications for pressure calibrations in experimental apparatus. American Mineralogist 100:1554-1561. https://doi.org/10.1111/j.1151-2916.2002.tb00389.x.

[58] Margueron S, Clarke D (2015) Refined crystal field model for the piezospectroscopy analysis of stresses in polycrystalline alumina. Journal of Applied Physics (118):094503. https://doi.org/10.1063/1.4929960.

[59] Ma Q, Clarke D (1994) Piezospectroscopic determination of residual stresses in polycrystalline alumina. Journal of the American Ceramic Society 77(2):298-302. https://doi.org/10.1111/j.1151-2916.1994.tb06996.x.

[60] Dauskardt R, Ager J III (1996) Quantitative stress mapping in alumina composites by optical fluorescence imaging. Acta Materialia 44(2):625-641. https://doi.org/10.1016/1359-6454(95)00189-1.

[61] Toyoda T, Obikawa T, Shigenari T (1998) Photoluminescence spectroscopy of $\mathrm{Cr}^{3+}$ in ceramic $\mathrm{Al}_{2} \mathrm{O}_{3}$. Materials Science and Engineering B54(1-2): 33-37. https://doi.org/10.1016/S0921-5107(98)00122-6.

[62] Jankowiak R, Roberts K, Tomasik P, Sikora M, Small G, Schilling C (2000) Probing the crystalline environment of $\alpha$-alumina via luminescence of metal ion impurities: An optical method of ceramic flaw detection. Materials Science and Engineering A281(1-2): 45-55. https://doi.org/10.1016/S0921-5093(99)00749-2.

[63] Narita Y, Murotani H (2002) Submicrometer optical characterization of the grain boundary of optically active $\mathrm{Cr}^{3+}$ doped polycrystalline $\mathrm{Al}_{2} \mathrm{O}_{3}$ by near-field spectroscopy. American Mineralogist 87:1144-1147. https://doi.org/10.2138/am-2002-8-912.

[64] Kortov V, Ermakov A, Zatsepin A, Nikiforov S (2008) Luminescence properties of nanostructured alumina ceramic. Radiation Measurements 43:341-344. https://doi.org/10.1016/j.radmeas.2007.10.008.

[65] Liu Q, Yang Q, Zhao G, Lu S, Zhang H (2013) The thermoluminescence and optically stimulated luminescence properties of Cr-doped alpha alumina transparent ceramics. Journal of Alloys and Compounds 579:259-262. https://doi.org/10.1016/j.jallcom.2013.06.070.

[66] Myers G, Michaels C, Cook R (2016) Quantitative mapping of stress heterogeneity in polycrystalline alumina using hyperspectral fluorescence microscopy. Acta Materialia 106:272-282. https://doi.org/10.1016/j.actamat.2016.01.020.

[67] Michaels C, Cook R (2016) Determination of residual stress distributions in polycrystalline alumina using fluorescence microscopy. Materials \& Design 107:478-490. https://doi.org/10.1016/j.matdes.2016.06.063.

[68] Ma Q, Pompe W, French J, Clarke D (1994) Residual stresses on $\mathrm{Al}_{2} \mathrm{O}_{3}-\mathrm{ZrO}_{2}$ composites: A test of stochastic stress models. Acta Metallurgica et Materialia 42(5):1673-1681. https://doi.org/10.1016/0956-7151(94)90377-8.

[69] Sergo V, Clarke D, Pompe W (1995) Deformation bands in ceria-stabilized zirconia/alumina: I, measurement of internal stresses. Journal of the American Ceramic Society 78(3):633-640. https://doi.org/10.1111/j.1151-2916.1995.tb08224.x. 
[70] Sergo V, Clarke D (1995) Deformation bands in ceria-stabilized zirconia/alumina: II, stress-induced aging at room temperature. Journal of the American Ceramic Society 78(3):641-644. https://doi.org/10.1111/j.1151-2916.1995.tb08225.x.

[71] Sergo V, Lipkin D, De Portu G, Clarke D (1997) Edge stresses in alumina/zirconia laminates. Journal of the American Ceramic Society 80(7):1633-1638. https://doi.org/10.1111/j.1151-2916.1997.tb03031.x.

[72] Sergo V, Pezzotti G, Sbaizero O, Nishida T (1998) Grain size influence on residual stresses on alumina/zirconia composites. Acta Materialia 46(5):1701-1710. https://doi.org/10.1016/S1359-6454(97)00348-0.

[73] Pardo J, Merino R, Orera V, Peña J, González C, Pastor J, LLorca J (2000) Piezospectroscopic study of residual stresses in $\mathrm{Al}_{2} \mathrm{O}_{3}-\mathrm{ZrO}_{2}$ directionally solidified eutectics. Journal of the American Ceramic Society 83(11):2745-2752. https://doi.org/10.1111/j.1151-2916.2000.tb01626.x.

[74] Ortiz Merino J Todd $\mathrm{R}$ (2003) Thermal microstress measurements in $\mathrm{Al}_{2} \mathrm{O}_{3} / \mathrm{SiC}$ nanocomposites by $\mathrm{Cr}^{3+}$ fluorescence microscopy. Journal of the European Ceramic Society 23(11):1779-1783. https://doi.org/10.1016/S0955-2219(02)00446-6.

[75] Peña J, Larsson M, Merino R, de Francisco I, Orera V, LLorca J, Pastor J, Martín, Segurado J (2006) Processing, microstructure and mechanical properties of directionally-solidified $\mathrm{Al}_{2} \mathrm{O}_{3}-\mathrm{Y}_{3} \mathrm{Al}_{5} \mathrm{O}_{12}-\mathrm{ZrO}_{2}$ ternary eutectics. Journal of the European Ceramic Society 26(15):3113-3121. https://doi.org/10.1016/j.jeurceramsoc.2005.11.005.

[76] Perrière L, Valle R, Carrère N, Gouadec G, Colomban Ph, Lartigue-Korinek S, Mazerolles L, Parlier M (2011) Crack propagation and stress distribution in binary and ternary directionally solidified eutectic ceramics. Journal of the European Ceramic Society 31(7):1199-1210. https://doi.org/10.1016/j.jeurceramsoc.2010.09.016.

[77] Gouadec G, Makoui K, Perrière L, Colomban Ph, Mazerolles L (2012) Ruby micro-piezospectroscopy in $\mathrm{GdAlO}_{3} / \mathrm{Al}_{2} \mathrm{O}_{3}\left(/ \mathrm{ZrO}_{2}\right)$, $\mathrm{Er}_{3} \mathrm{Al}_{5} \mathrm{O}_{12} / \mathrm{Al}_{2} \mathrm{O}_{3}\left(/ \mathrm{ZrO}_{2}\right)$ and $\mathrm{Y}_{3} \mathrm{Al}_{5} \mathrm{O}_{12} / \mathrm{Al}_{2} \mathrm{O}_{3}\left(/ \mathrm{ZrO}_{2}\right)$ binary and ternary directionally solidified eutectics. Journal of the European Ceramic Society 32(10):2145-2151. https://doi.org/10.1016/j.jeurceramsoc.2012.01.038.

[78] Benamara O, Cherif M, Duffar T, Lebbou K (2015) Microstructure and crystallography of $\mathrm{Al}_{2} \mathrm{O}_{3}-\mathrm{Y}_{3} \mathrm{Al}_{5} \mathrm{O}_{12}-\mathrm{ZrO}_{2}$ ternary eutectic oxide grown by the micropulling down technique. Journal of Crystal Growth 429:27-34. https://doi.org/10.1016/j.jcrysgro.2015.07.020.

[79] Liu H, Lim K, Jia W, Strauss E, Yen W, Buoncristiani A, Byvik C (1988) Effects of tensile stress on the R lines of $\mathrm{Cr}^{3+}$ in sapphire fiber. Optics Letters 13(10):931-933. https://doi.org/10.1364/OL.13.000931.

[80] Ma Q, Clarke D (1993) Measurement of residual stresses in sapphire fiber composites using optical fluorescence. Acta Metallurgica et Materialia 41(6):1817-1823. https://doi.org/10.1016/0956-7151(93)90202-4.

[81] Ma Q, Liang L, Clarke D, Hutchinson J (1994) Mechanics of the push-out process from in situ measurement of the stress distribution along embedded sapphire fibers. Acta Metallurgica et Materialia 42(10):3299-3308. https://doi.org/10.1016/09567151(94)90462-6.

[82] Yang X, Young R (1995) Determination of residual strains in ceramic-fibre reinforced composites using fluorescence spectroscopy. Acta Metallurgica et Materialia 43(6):2407-2416. https://doi.org/10.1016/0956-7151(94)00438-2.

[83] Young R, Yang X (1996) Interfacial failure in ceramic fibre/glass composites. Composites Part A 27:737-741. https://doi.org/10.1016/1359-835X(96)00022-X.

[84] Yallee R, Andrews M, Young R (1996) Fragmentation in alumina fibre reinforced epoxy model composites monitored using fluorescence spectroscopy. Journal of Materials Science 31(13):3349-3359. https://doi.org/10.1007/BF00360734.

[85] He J, Clarke D (1997) Determination of fibre strength distributions from bundle tests using optical luminescence spectroscopy. Proceedings of the Royal Society of London A 453(1954):1881-1901. https://doi.org/10.1098/rspa.1997.0101.

[86] Belnap J, Shetty D (1998) Micromechanics of crack bridging in sapphire/epoxy composites. Composites Science and Technology 58(11):1763-1773. https://doi.org/10.1016/S0266-3538(98)00042-6.

[87] Mahiou H, Beakou A, Young R (1999) Investigation into stress transfer characteristics in alumina-fibre/epoxy model composites through the use of fluorescence spectroscopy. Journal of Materials Science 34(24):6069-6080. https://doi.org/10.1023/A:1004705500981.

[88] He J, Beyerlein I, Clarke D (1999) Load transfer from broken fibers in continuous fiber $\mathrm{Al}_{2} \mathrm{O}_{3}$ - $\mathrm{Al}$ composites and dependence on local volume fraction. Journal of the Mechanics and Physics of Solids 47(3):465-502. https://doi.org/10.1016/S00225096(98)00053-2.

[89] Sinclair, R, Young R, Martin R (2004) Determination of the axial and radial fibre stress distributions for the Broutman test. Composites Science and Technology 64(2):181-189. https://doi.org/10.1016/S0266-3538(03)00257-4.

[90] Dassios K, Galiotis C (2004) Fluorescence studies of polycrystalline $\mathrm{Al}_{2} \mathrm{O}_{3}$ composite constituents: piezo-spectroscopic calibration and applications. Appl. Phys. A 79(3):647-659. https://doi.org/10.1007/s00339-002-2075-3.

[91] Belnap J, Shetty D (2005) Interfacial properties of sapphire/epoxy composites: Comparison of fluorescence spectroscopy and fiber push-in techniques. Composites Science and Technology 65(11-12):1851-1860. https://doi.org/10.1016/j.compscitech.2005.03.013.

[92] Wen Q, Clarke D, Yu N, Nastasi M (1995) Epitaxial regrowth of ruby on sapphire for an integrated thin film stress sensor. Applied Physics Letters 66(3):293-295. https://doi.org/ 10.1063/1.113522.

[93] Wen Q, Ma, Q, Clarke D (1994) In-situ fluorescence strain sensing of the stress in interconnects. Thin Films and Mechanical Properties V, MRS Proceedings 356:591-598. https://doi.org/10.1557/PROC-356-591.

[94] Yu N, Wen Q, Clarke D, McIntyre P, Kung H, Nastasi M, Simpson T, Mitchell I, Li D (1995) Formation of iron or chromium doped epitaxial sapphire thin films on sapphire substrates. Journal of Applied Physics 78(9):5412-5421. https://doi.org/10.1063/1.359722.

[95] Kumari S, Khare A (2011) Note: Epitaxial ruby thin film based photonic sensor for temperature measurement. Review of Scientific Instruments 82:066106. https://doi.org/10.1063/1.3606443.

[96] Lipkin D, Clarke D (1996) Measurement of the stress in oxide scales formed by oxidation of alumina-forming alloys. Oxidation Metals 45(3/4):267-280. https://doi.org/10.1007/BF01046985.

[97] Christensen R, Lipkin D, Clarke D, Murphy K (1996) Nondestructive evaluation of the oxidation stresses through thermal barrier coatings using $\mathrm{Cr}^{3+}$ piezospectroscopy. Journal of Applied Physics 69(24):3752-3756. https://doi.org/10.1063/1.117182. 
[98] Christensen R, Lipkin D, Clarke D (1996) The stress and spalling behavior of the oxide scale formed on polycrystalline $\mathrm{Ni}_{3} \mathrm{Al}$. Acta Materialia 44(9):3813-3821. https://doi.org/10.1016/1359-6454(96)00009-2.

[99] Gong X, Clarke D (1998) On the measurement of strain in coatings formed on a wrinkled elastic substrate. Oxidation Metals 50(6/5):355-376. https://doi.org/10.1023/A:1018848607100.

[100] Tolpygo V, Clarke D (1998) Competition between stress generation and relaxation during oxidation of an Fe-Cr-Al-Y alloy. Oxidation Metals 49(1/2):187-212. https://doi.org/10.1023/A:1018828619028.

[101] Tolpygo V, Clarke D (1998) Wrinkling of $\alpha$-alumina films grown by thermal oxidation-I. Quantitative studies on single crystals of Fe-Cr-Al alloy. Acta Materialia 46(14):5153-5166. https://doi.org/10.1016/S1359-6454(98)00133-5.

[102] Tolpygo V, Clarke D (1998) Wrinkling of $\alpha$-alumina films grown by thermal oxidation-II. Oxide separation and failure. Acta Materialia 46(14):5167-5174. https://doi.org/10.1016/S1359-6454(98)00134-7.

[103] Tolpygo V, Clarke D (2000) Spalling failure of $\alpha$-alumina films grown by oxidation: I. Dependence on cooling rate and metal thickness. Materials Science and Engineering A278:142-150. https://doi.org/10.1016/S0921-5093(99)00581-X.

[104] Tolpygo V, Clarke D (2000) Spalling failure of $\alpha$-alumina films grown by oxidation: II. Decohesion nucleation and growth. Materials Science and Engineering A278:151-161. https://doi.org/10.1016/S0921-5093(99)00582-1.

[105] Schlichting K, Vaidyanathan K, Sohn Y, Jordan E, Gell M, Padture N (2000) Application of $\mathrm{Cr}^{3+}$ photoluminescence piezospectroscopy to plasma-sprayed thermal barrier coatings for residual stress measurement. Materials Science and Engineering A291:68-77. https://doi.org/10.1016/S0921-5093(00)00973-4.

[106] Atkinson A, Selçuk A, Webb S (2000) Variability of stress in alumina corrosion layers formed in thermal-barrier coatings. Oxidation Metals 54(5/6):371-384. https://doi.org/10.1023/A:1004613332338.

[107] Nychka J, Clarke D (2001) Damage quantification in TBCs by photo-stimulated luminescence spectroscopy. Surface and Coatings Technology 146-147:110-116. https://doi.org/10.1016/S0257-8972(01)01455-4.

[108] Selçuk A, Atkinson A (2002) Analysis of the $\mathrm{Cr}^{3+}$ luminescence spectra from thermally grown oxide in thermal barrier coatings. Materials Science and Engineering A335:147-156. https://doi.org/10.1016/S0921-5093(01)01911-6.

[109] Selçuk A, Atkinson A (2003) The evolution of residual stress in the thermally grown oxide on Pt diffusion bond coats in TBCs. Acta Materialia 51(2):535-549. https://doi.org/10.1016/S1359-6454(02)00436-6.

[110] Nychka J, Clarke D, Sridharan S, Jordan E, Gell M, Lance M, Chunnilall C, Smith I, Saunders S, Pillane R, Sergo V, Selçuk A, Atkinson A, Murphy K (2003) NDE assessment of TBCs: An interim report of a photo-stimulated luminescence 'round-robin' test. Surface and Coatings Technology 163-164:87-94. https://doi.org/10.1016/S0257-8972(02)00596-0.

[111] Nychka J, Xu T, Clarke D, Evans A (2004) The stresses and distortions caused by formation of a thermally grown alumina: Comparison between measurements and simulations. Acta Materialia 52(9):2561-2568. https://doi.org/10.1016/j.actamat.2004.02.004.

[112] Peng X, Sridhar N, Clarke D (2004) The stress distribution around holes in thermal barrier coatings. Materials Science and Engineering A380:208-214. https://doi.org/10.1016/j.msea.2004.03.062.

[113] Tomimatsu T, Zhu S, Kagawa Y (2004) Local stress distribution in thermally-grown-oxide layer by near-field optical microscopy. Scripta Materialia 50(1):137-141. https://doi.org/10.1016/j.scriptamat.2003.09.005.

[114] Hovis A, Heuer A (2005) Confocal photo-stimulated microspectroscopy (CPSM)—Residual stress measurements in $\mathrm{Al}_{2} \mathrm{O}_{3}$ using confocal microscopy. Scripta Materialia 53(3):347-349. https://doi.org/10.1016/j.scriptamat.2005.04.016.

[115] Margueron S, Clarke D (2006) The use of polarization in the piezospectroscopic determination of the residual stresses in polycrystalline alumina films. Acta Materialia 54(20):5551-5557. https://doi.org/10.1016/j.actamat.2006.08.017.

[116] Ohtsuka S, Zhu W, Tochino S, Sekiguchi Y, Pezzotti G (2007) In-depth analysis of residual stress in an alumina coating on silicon nitride substrate using confocal Raman piezo-spectroscopy. Acta Materialia 55(4):1129-1135. https://doi.org/10.1016/j.actamat.2006.05.038.

[117] Clarke D, Gardiner D (2007) Recent advances in piezospectroscopy. International Journal of Materials Research 98(8):756762. https://doi.org/10.3139/146.101528.

[118] Gardiner D, Bowden M, Margueron S, Clarke D (2007) Use of polarization in imaging the residual stresses in polycrystalline alumina films. Acta Materialia 55(10):3431-3436. https://doi.org/10.1016/j.actamat.2007.01.044.

[119] Heeg B, Tolpygo V, Clarke D (2011) Damage evolution in thermal barrier coatings with thermal cycling. Journal of the American Ceramic Society 94(S1):S112-S119. https://doi.org/10.1111/j.1551-2916.2011.04496.x.

[120] Ostertag C, Robins L, Cook L (1991) Cathodoluminescence measurement of strained alumina single crystals. Journal of the European Ceramic Society 7(2):109-116. https://doi.org/10.1016/0955-2219(91)90008-N.

[121] Pezzotti G, Sbaizero O, Sergo V, Muraki N, Maruyama K, Nishida T (1998) In situ measurements of frictional bridging stresses in alumina using fluorescence spectroscopy. Journal of the American Ceramic Society 81(1):187-192. https://doi.org/10.1111/ j.1151-2916.1998.tb02312.x.

[122] Pezzotti G (1999) In situ study of fracture mechanisms in advanced ceramics using fluorescence and Raman microprobe spectroscopy. Journal of Raman Spectroscopy 30(10):867-875. https://doi.org/10.1002/(SICI)10974555(199910)30:10<867::AID-JRS466>3.0.CO;2-0.

[123] Pezzotti G, Okuda H, Muraki N, Nishida T (1999) In-situ determination of bridging stresses in $\mathrm{Al}_{2} \mathrm{O}_{3} / \mathrm{Al}_{2} \mathrm{O}_{3}$-platelet composites by fluorescence spectroscopy. Journal of the European Ceramic Society 19(5):601-608. https://doi.org/10.1016/S09552219(98)00230-1.

[124] Pezzotti G, Suenobu H, Nishida T (1999) Measurement of microscopic bridging stresses in an alumina/molybdenum composite by in situ fluorescence spectroscopy. Journal of the American Ceramic Society 82(5):1257-1262. https:// doi.org/10.1111/j.1151-2916.1999.tb01904.x.

[125] Banini G, Chaudhri M, Smith T, Hayward I (2001) Measurement of residual stresses around Vickers indentations in a ruby crystal using a Raman luminescence microscope. Journal of Physics D: Applied Physics 34:L122-L124. https://doi.org/10.1088/0022-3727/34/22/103. 
[126]Pezzotti G, Müller W (2002) Micromechanics of fracture in a ceramic/metal composite studied by in situ fluorescence spectroscopy I: Foundations and stress analysis. Continuum Mechanics and Thermodynamics 14(1):113-126. https://doi.org/10.1007/s001610100076.

[127]Todd R, Stowe D, Galloway S, Barnes D, Wilshaw P (2008) Piezospectroscopic measurement of the stress field around an indentation crack tip in ruby using SEM cathodoluminescence. Journal of the European Ceramic Society 28(10):2049-2055. https://doi.org/10.1016/j.jeurceramsoc.2008.02.008.

[128]Wu H, Roberts S, Derby B (2008) Residual stress distributions around indentations and scratches in polycrystalline $\mathrm{Al}_{2} \mathrm{O}_{3}$ and $\mathrm{Al}_{2} \mathrm{O}_{3} / \mathrm{SiC}$ nanocomposites measured using fluorescence probes. Acta Materialia 56(1):140-149. https://doi.org/10.1016/j.actamat.2007.09.014.

[129] Guo S, Todd R (2010) $\mathrm{Cr}^{3+}$ microspectroscopy measurements and modelling of local variations in surface grinding stresses in polycrystalline alumina. Journal of the European Ceramic Society 30(12):2533-2545. https://doi.org/10.1016/j.jeurceramsoc.2010.04.016.

[130] Guo S, Limpichaipanit A, Todd R (2011) High resolution optical microprobe investigation of surface grinding stresses in $\mathrm{Al}_{2} \mathrm{O}_{3}$ and $\mathrm{Al}_{2} \mathrm{O}_{3} / \mathrm{SiC}$ nanocomposites. Journal of the European Ceramic Society 31(1-2):97-109. https://doi.org/10.1016/j.jeurceramsoc.2010.08.021.

[131] Guo S, Todd R (2011) Quantitative optical fluorescence microprobe measurements of stresses around indentations in $\mathrm{Al}_{2} \mathrm{O}_{3}$ and $\mathrm{Al}_{2} \mathrm{O}_{3} / \mathrm{SiC}$ nanocomposites: The influence of depth resolution and specimen translucency. Acta Materialia 59(7):2637-2647. https://doi.org/10.1016/j.actamat.2010.12.055.

[132] Dancer C, Curtis H, Bennett S, Petrinic N, Todd R (2011) High strain rate indentation-induced deformation in alumina ceramics measured by $\mathrm{Cr}^{3+}$ fluorescence mapping. Journal of the European Ceramic Society 31(13):2177-2187. https://doi.org/10.1016/j.jeurceramsoc.2011.06.002.

[133] Greene R, Gallops S, Fünfschilling S, Fett T, Hoffmann M, Ager J III, Kruzic J (2012) A direct comparison of non-destructive techniques for determining bridging stress distributions. Journal of the Mechanics and Physics of Solids 60(8):1462-1477. https://doi.org/10.1016/j.jmps.2012.04.007.

[134] Huang S, Binnera J, Vaidhyanathana B, Todd R (2014) Quantitative analysis of the residual stress and dislocation density distributions around indentations in alumina and zirconia toughened alumina (ZTA) ceramics. Journal of the European Ceramic Society 34(3):753-763. https://doi.org/10.1016/j.jeurceramsoc.2013.09.021.

[135] Munro R, Piermarini G, Block S, Holzapfel W (1985) Model line-shape analysis for the ruby R lines used for pressure measurement. Journal of Applied Physics 57(2):165-169. https://doi.org/10.1063/1.334837.

[136] Grasset O (2001) Calibration of the R ruby fluorescence lines in the pressure range [0-10 GP] and the temperature range [250300 K]. High Pressure Research 21:139-157. https://doi.org/10.1080/08957950108201020.

[137] Mase G (1970) Continuum Mechanics (The McGraw-Hill Companies, New York).

[138]Friedman L, Vaudin M, Stranick S, Stan G, Gerbig Y, Osborn W, Cook R (2016) Assessing strain mapping by electron backscatter diffraction and confocal Raman microscopy using wedge-indented Si. Ultramicroscopy 163:75-86. https://doi.org/10.1016/j.ultramic.2016.02.001.

[139]Kaplyanskii A, Przhevuskii A, Roezenbaum R (1969) Concentration-dependent line-shift in optical spectra of ruby. Soviet Physics-Solid State 10(8):1864-1868.

[140] Schawlow A (1961) Fine structure and properties of chromium fluorescence in aluminum and magnesium oxide. Advances in Quantum Electronics, ed Singer JR (Columbia University Press, New York), pp 50-64.

[141] Gibson U, Chernuschenko M (1999) Ruby films as surface temperature and pressure sensors. Optics Express 4(11):443-448. https://doi.org/10.1364/OE.4.000443.

[142]Paetzold H (1951) Über den Temperature- und Druckeinfluss auf Elecktroenterme in Kristallen. Zeitschrift für Physik 129(2):123-139 (in German). https://doi.org/10.1007/BF01333392.

[143]Langer D, Euwema R (1967) Pressure shift of the Cr levels in $\mathrm{Al}_{2} \mathrm{O}_{3}$. Journal of the Physics and Chemistry of Solids 28(3):463465. https://doi.org/10.1016/0022-3697(67)90315-0.

[144]Ragan D, Clarke, D, Schiferl D (1996) Silicone fluid as a high-pressure medium in diamond anvil cells. Review of Scientific Instruments 67(2):494-496. https://doi.org/10.1063/1.1146627.

[145]Liu L, Bi Y, Xu J (2013) Ruby fluorescence pressure scale: Revisited. Chinese Physics B 22(5):056201-1-5. https://doi.org/10.1088/1674-1056/22/5/056201.

[146]Kaplyanskii A, Przhevuskii A (1962) The piezospectroscopic effect in ruby crystals. Soviet Physics-Doklady 7(1):37-40.

[147] Sturge M (1965) Effect of stress on the level splittings of ruby: Origin of the ground-state splitting. Journal of Chemical Physics 43(5):1826-1827. https://doi.org/10.1063/1.1697015.

[148]Feher E, Sturge M (1968) Effect of stress on the trigonal splittings of $d^{3}$ ions in sapphire $\left(\alpha-\mathrm{A}_{2} \mathrm{O}_{3}\right)$. Physical Review 172(2):244-249. https://doi.org/10.1103/PhysRev.172.244.

[149] Fujishiro I, Nakamura Y, Kawase T, Okai B (1988) The property of a ruby high pressure sensor under uniaxial compressive stress. Japan Society of Mechanical Engineers International Journal Series 3 31(1):136-141. https://doi.org/10.1299/jsmec1988.31.136.

[150]Horn P, Gupta Y (1989) Luminescence R-line spectrum of ruby crystals shocked to $125 \mathrm{kbar}$ along the crystal $c$ axis. Physical Review B 39(2):973-979. https://doi.org/10.1103/PhysRevB.39.973.

[151] Gupta Y, Shen X (1991) Potential use of the ruby $\mathrm{R}_{2}$ line shift for static high-pressure calibration. Applied Physics Letters 58 (6):583-585. https://doi.org/10.1063/1.104594.

[152] McCumber D, Sturge M (1963) Linewidth and temperature shift of the R lines in ruby. Journal of Applied Physics 34(6):16821684. https://doi.org/10.1063/1.1702657.

[153]Powell R, DiBartolo B, Birang B, Naiman C (1966) Temperature dependence of the widths and positions of the R and N lines in heavily doped ruby. Journal of Applied Physics 37(13):4973-4978. https://doi.org/10.1063/1.1708175.

[154]Yen J, Nicol M (1992) Temperature dependence of the ruby luminescence method for measuring high pressures. Journal of Applied Physics 72(12):5535-5538. https://doi.org/10.1063/1.351950. 
[155]Ragan D, Gustavsen R, Schiferl D (1992) Calibration of the ruby $R_{1}$ and $R_{2}$ fluorescence shifts as a function of temperature from 0 to 600 K. Journal of Applied Physics 72(12):5539-5544. https://doi.org/10.1063/1.351951.

[156]Huang T-H, Hsu C-C, Kuo C-T, Lu P, Tse, W-S, Wang D, Chou T, Fuh A (1994) Ruby spectral band-profile analysis for temperature sensing. Journal of Applied Physics 75(7):3599-3606. https://doi.org/10.1063/1.356071.

[157]Powell R, DiBartolo B, Birang, B, Naiman C (1967) Fluorescence studies of energy transfer between single and pair $\mathrm{Cr}^{3+}$ systems in $\mathrm{Al}_{2} \mathrm{O}_{3}$. Physical Review 155(2):296-308. https://doi.org/10.1103/PhysRev.155.296.

[158]Kaplyanskii A, Przhevskii A (1967) Deformational splitting of luminescence spectrum lines and the structure of exchange-linked pairs of chromium ions in ruby. Soviet Physics-Solid State 9(1):190-198.

[159] Mollenauer L, Schawlow A (1968) Piezospectroscopic studies of exchange-coupled $\mathrm{Cr}^{3+}$ ion pairs in ruby. Physical Review 168(2):309-317. https://doi.org/10.1103/PhysRev.168.309.

[160]Powell R, DiBartolo B (1972) Review Article: Optical properties of heavily doped ruby. Physica Status Solidi (a) 10(2):315357. https://doi.org/10.1002/pssa.2210100202.

[161]Williams Q, Jeanloz R (1985) Pressure shift of $\mathrm{Cr}^{3+}$-ion-pair emission lines in ruby. Physical Review B 31(11):7449-7451. https://doi.org/10.1103/PhysRevB.31.7449.

[162] Margueron S (2017) Private communication of unpublished work.

[163] Anderson A (1995) Equations of State of Solids for Geophysics and Ceramic Science (Oxford University Press, Oxford).

[164]Becquerel E (1859) Recherches sur divers effets lumineux qui resultant de l'action de la lumière sur les corps. Annales de Chimie et de Physique 17(3):40-128. http://gallica.bnf.fr/ark:/12148/bpt6k65671381/f511.item.

[165] Taylor J (1997) An Introduction to Error Analysis (University Science Books, Herndon, VA), 2nd Ed.

About the authors: Dr. Robert F. Cook is a NIST Fellow in the Materials Measurement Science Division at NIST. Dr. Cook performs research on mechanics and mechanical behavior of materials, with a focus on fracture and deformation of brittle materials.

Dr. Chris A. Michaels is a Research Chemist in the Materials Measurement Science Division at NIST. Dr. Michaels develops and applies high-spatial-resolution spectroscopic techniques and instrumentation to the study of materials.

The National Institute of Standards and Technology is an agency of the U.S. Department of Commerce. 